\title{
SENTIMENT AND THE U.S. BUSINESS CYCLE
}

\author{
FABIO MILANI \\ University of CALifornia, Irvine
}

\begin{abstract}
Psychological factors are commonly believed to play a role on cyclical economic fluctuations, but they are typically omitted from state-of-the-art macroeconomic models.

This paper introduces "sentiment" in a medium-scale DSGE model of the U.S. economy and tests the empirical contribution of sentiment shocks to business cycle fluctuations.

The assumption of rational expectations is relaxed. The paper exploits, instead, observed data on expectations in the estimation. The observed expectations are assumed to be formed from a near-rational learning model. Agents are endowed with a perceived law of motion that resembles the model solution under rational expectations, but they lack knowledge about the solution's reducedform coefficients. They attempt to learn those coefficients over time using available time series at each point in the sample and updating their beliefs through constant-gain learning. In each period, however, they may form expectations that fall above or below those implied by the learning model. These deviations capture excesses of optimism and pessimism, which can be quite persistent and which are defined as sentiment in the model. Different sentiment shocks are identified in the empirical analysis: waves of undue optimism and pessimism may refer to expected future consumption, future investment, or future inflationary pressures.

The results show that exogenous variations in sentiment are responsible for a sizable (above forty percent) portion of historical U.S. business cycle fluctuations. Sentiment shocks related to investment decisions, which evoke Keynes' animal spirits, play the largest role. When the model is estimated imposing the rational expectations hypothesis, instead, the role of structural investmentspecific and neutral technology shocks significantly expands to capture the omitted contribution of sentiment.
\end{abstract}

Keywords: Sentiment, Animal Spirits, Learning, DSGE Model, Sources of Business Cycle Fluctuations, Observed Survey Expectations.

JEL classification: E03, E32, E50, E52, E58.

I would like to thank participants at the Society of Economic Dynamics Meeting in Toronto, at the "Econometrics for Macroeconomics and Finance" Workshop at Hitotsubashi University in Kunitachi, Japan, at the "Expectations in Dynamic Macroeconomic Models" Workshops at the University of St. Andrews, Scotland, and at the Federal Reserve Bank of San Francisco, at the Royal Economic Society Meeting at Royal Holloway, at the Midwest Macroeconomics Meetings at the University of Colorado, Boulder, at the Ghent University Workshop on Empirical Macroeconomics, particularly the paper's discussant Raffaella Giacomini, as well as seminar participants at the Bank of Canada, Bank of England, the Bank for International Settlements, Bank of Korea, Cal State Fullerton, Copenhagen Business School, and Louisiana State University, for various comments and discussions.

Address for correspondence: Department of Economics, 3151 Social Science Plaza, University of California, Irvine, CA 92697-5100. Phone: 949-824-4519. Fax: 949-824-2182. E-mail: fmilani@uci.edu. Homepage: http://www.socsci.uci.edu/ fmilani. 


\section{INTRODUCTION}

Economists have always recognized the importance of expectations for aggregate economic behavior. Some of the most influential economic thinkers of the past century attributed explicitly to the volatility of expectations a prime role in explaining the existence and depth of business cycles.

Keynes emphasized in the General Theory the importance of changes in expectations that are not necessarily driven by rational probabilistic calculations, but which are rather motivated by what he famously labeled "animal spirits". In particular, entrepreneurs' animal spirits related to their investment decisions were theorized of being a major determinant of economic fluctuations. Pigou (1927) also thought of business cycles as being largely driven by expectations and he stressed entrepreneurs' errors of optimism and pessimism as key drivers of fluctuations in real activity.

Expectations maintain a central, although different, role in modern state-of-the-art general equilibrium models. Expectations are almost universally modeled as formed according to the rational expectations hypothesis. As a result, at least in models with a determinate equilibrium, expectational errors can be solved out as a function of fundamental shocks and they disappear as autonomous sources of dynamics. Hence, there is typically no scope for fluctuations in expectations in the spirit of those emphasized by Keynes, which are driven by animal spirits, market psychology, sentiment, or by any expectational shift that cannot be reconnected to primitive structural disturbances. $^{1}$

In state-of-the-art DSGE models, the main sources of fluctuations are typically shocks to demand, such as exogenous shifts in preferences, risk-premia, and monetary and fiscal policies, shocks related to technology, such as Hicks-neutral or investment specific technology shocks, or to market power, such as price and wage markup shocks. While the empirical DSGE macro literature disagrees on the relative contributions of each shock, most of it implicitly agrees on assigning a nil role to explanations based on non-fundamental expectational shifts, such as swings in sentiment that are not necessarily motivated by fundamentals.

This paper aims to fill this gap in the literature. It revisits a benchmark DSGE model that is often used to characterize the dynamics of the U.S. economy at business cycle frequencies. But the model is extended to incorporate "sentiment", which represents waves of optimism and pessimism that are exogenous to the state of the economy.

\footnotetext{
${ }^{1}$ Animal spirits may, instead, be reintroduced under rational expectations by assuming equilibrium indeterminacy: the expectational errors in that case are not only a function of structural disturbances, but also of exogenous sunspot variables. There is a conspicuous literature, surveyed in Benhabib and Farmer (1999), which is focused on studying indeterminacy and sunspots in macroeconomic models. The work in this area has, however, been more often theoretical than empirical (Lubik and Schorfheide, 2004, is an exception, providing an econometric analysis of sunspots in a general equilibrium model). This paper's approach differs from the indeterminacy literature as it can imply self-fulfilling fluctuations even when the equilibrium is unique.
} 
The stringent informational requirements of rational expectations are relaxed. In their place, I will exploit observed data on expectations, obtained from the Survey of Professional Forecasters, in the estimation.

The observed expectations are assumed to be, on average, the outcome of a near-rational expectation formation process, which allows for learning by economic agents. Agents form expectations based on a linear model that has the same structural form of the system solution under rational expectations (i.e., the model used by agents is correctly-specified, since it contains the same regressors). The paper, however, relaxes the assumption that economic agents in the model have an informational advantage over the econometrician estimating the model. Here, at each point in the sample, economic agents can observe only historical data up to that point and they form beliefs about the reduced-form model coefficients by estimating simple regressions. The framework allows for deviations from rational expectations, but the deviation is meant to be small: agents still use a correctly-specified model. Such small deviations set the learning literature apart from starker alternatives that abandon rational expectations to assume, for example, simple heuristic rules (e.g., De Grauwe, 2012).

Although expectations are formed, on average, from the learning model, economic agents can, in every period, form expectations that deviate from the point forecasts that their learning model yields. These deviations of actual expectations from their levels that can be explained by a nearrational model with learning are interpreted as denoting exogenous waves of undue optimism or pessimism, and define the "sentiment" terms in the model. Sentiment shocks are, therefore, identified from the dynamic interactions between observed expectations and realized macroeconomic time series.

The DSGE model is estimated using Bayesian techniques and adding data on observed expectations about consumption, investment, and inflation to the set of observables to match. The main scope in the empirical analysis lies in studying the empirical contribution of these newly-defined sentiment shocks to macroeconomic fluctuations.

Main Results. The empirical results show that sentiment shocks explain a sizable portion of U.S. business cycle fluctuations. Sentiment explains more than forty percent of the variability of output and consumption at horizons between one year and six years, and around sixty percent of the variability of investment and inflation. The most important component of sentiment consists of sentiment related to future investment expectations, which is found to be the single main driver of business cycle movements. Inflation is driven by structural price markup shocks in the short-run; 
their transmission is, however, very quick, and market participants' sentiment about inflationary pressures becomes predominant at frequencies above one year.

If learning and sentiment are shut down and the conventional assumption of rational expectations is re-imposed, technology shocks become the dominant source of aggregate fluctuations (in both forms of investment-specific and neutral technology shocks), as theorized by the RBC literature. The contribution of technological changes for booms and busts significantly rises to close the gap induced by the omitted role of households and firms' sentiment.

When the model is estimated under observed expectations, allowing for learning and sentiment, the degrees of some real and nominal frictions necessary to fit the data is diminished. In particular, moving away from rational expectations attenuates the degree of habit formation in consumption and sharply reduces the magnitude of adjustment costs in investment. The estimated autocorrelation of several structural disturbances is largely reduced and the responses of macroeconomic variables to some structural shocks become faster than usually estimated. Sentiment, on the other hand, is responsible for more sluggish adjustment in the economy.

Related Literature. In previous related work (Milani, 2011), I modeled expectation shocks and showed that they potentially play a large role as drivers of business cycles. That paper used a stylized three-equation New Keynesian model. The current paper extends the analysis to a more comprehensive and empirically relevant model of the U.S. economy. While the previous paper abstracted from capital accumulation, this work includes capital and investment, allowing for adjustment costs and variable capital utilization, in addition to features such as monopolistic competition in the labor market, wage stickiness, habit formation in consumption, and it exploits expectations about future consumption and investment in the estimation. In this way, the paper can disentangle the role of sentiment related to consumers' expenditure decisions and to firm's investment choices, which was the channel emphasized in Keynes' theories.

The paper adds to the expanding literature on bounded rationality and learning in macroeconomics (e.g., Evans and Honkapohja, 2001, Sargent, 1993). It exploits direct data on expectations to inform the estimation of the best-fitting learning process over the sample. Moreover, it shows that, in addition to the role of learning, a different component of expectations, which the paper defines as sentiment, is key to understand business cycles. A particularly related paper in the learning literature is Bullard et al. (2009), who introduce judgment in economic agents' learning model, showing that it can lead to near-rational exuberance equilibria. Eusepi and Preston (2011) show that learning can amplify business cycle fluctuations in a baseline RBC model driven by technology shocks. 
On the methodological side, the DSGE literature has only recently started to include data on expectations in the estimation of DSGE models. Del Negro and Eusepi (2011) use data on inflation expectations to test whether rational expectations DSGE models can successfully explain the expectation series; Ormeno (2010) adds information from observed inflation expectations to discipline the estimation of models with learning. Milani (2011) introduces data on expectations regarding output, inflation, and interest rates. Aruoba and Schorfheide (2011) exploit long-run inflation expectations to help extract the implicit Federal Reserve's inflation target. Hirose and Kurozumi (2012) and Milani and Rajbhandari (2012b) exploit a large set of expectations series at different horizons to enhance the identification of news shocks.

The paper can be connected to the literature on multiple equilibria, sunspots, and animal spirits, although most of the modeling choices differ. The paper can be seen as an econometric evaluation of the importance of animal spirits, here defined somewhat differently, since they arise in a model in which rational expectations have been relaxed. An advantage of the approach suggested in this paper is that the existence of self-fulfilling fluctuations in expectations are not conditional on indeterminacy of the equilibrium, which in a model as the one considered in this paper, would be mostly due to a failure by monetary policy to satisfy the Taylor principle. Self-fulfilling fluctuations and expectations-driven business cycles may arise here in a model in which monetary policy still responds aggressively toward inflation and a unique determinate equilibrium exists. ${ }^{2}$

The paper has also points of contact with the literature on news and anticipated shocks (e.g., Beaudry and Portier, 2006, Blanchard et al, 2013). That literature has mostly emphasized news about future technology as sources of fluctuations, although recently other types of news have been considered (e.g., Fujiwara et al, 2011, Khan and Tsoukalas, 2011, Schmitt-Grohe and Uribe, 2012, and Milani and Treadwell, 2011). The sentiment variables identified here do not represent news about future improvements in technology or future monetary or fiscal policies, but they are intended to capture unjustified and possibly persistent waves of optimism and pessimism that are orthogonal to the observed state of the economy. The paper shows that the identified sentiment in the model is indeed correlated to innovations obtained from available survey data on sentiment, supporting the interpretation proposed in this paper.

Finally, other recent studies have, instead, focused on second-moment, rather than first-moment shocks, by investigating the potential for uncertainty shocks as a source of economic fluctuations (e.g., Bloom, 2009). I abstract from those here.

\footnotetext{
${ }^{2}$ The feature of self-fulfilling fluctuations in a model with a unique equilibrium is shared by the paper by Angeletos and La'O (2013). Their theoretical framework is entirely different, with sentiment or animal spirits arising from imperfect communication among agents living in separate islands. Their work maintains rational expectations.
} 


\section{MODEL}

The current generation of DSGE models joins elements from the RBC tradition (explicit microfoundations, dynamic optimization, capital accumulation, and technology shocks) and elements from the New Keynesian tradition (imperfect competition, sticky prices, sticky wages, an interest rate rule for monetary policy). Economic agents are typically assumed to form model-consistent rational expectations. To be taken to the data, the model needs to incorporate a variety of real and nominal frictions, along with a combination of serially-correlated exogenous shocks.

This paper follows in this tradition by assuming that fluctuations in the U.S. economy at business cycle frequencies can be summarized by a medium-scale DSGE model, based on Christiano et al. (2005) and Smets and Wouters (2007), and which has been used as benchmark in several studies. Similar models have been developed and fitted to U.S. data by Justiniano et al. (2010), Del Negro et al. (2007), among countless others. Since later we will relax the assumption of rational expectations, we replace the mathematical expectation operator $E_{t}$ with the indicator for subjective expectations $\widehat{E}_{t}$. We report the set of loglinearized equations here. ${ }^{3}$

$$
\begin{aligned}
y_{t} & =c_{y} c_{t}+i_{y} i_{t}+u_{y} u_{t}+\varepsilon_{t}^{g} \\
c_{t} & =c_{1} c_{t-1}+\left(1-c_{1}\right) \widehat{E}_{t} c_{t+1}+c_{2}\left(l_{t}-\widehat{E}_{t} l_{t+1}\right)-c_{3}\left(r_{t}-\widehat{E}_{t} \pi_{t+1}+\varepsilon_{t}^{b}\right) \\
i_{t} & =i_{1} i_{t-1}+\left(1-i_{1}\right) \widehat{E}_{t} i_{t+1}+i_{2} q_{t}+\varepsilon_{t}^{i} \\
q_{t} & =q_{1} \widehat{E}_{t} q_{t+1}+\left(1-q_{1}\right) \widehat{E}_{t} r_{t+1}^{k}-\left(r_{t}-\widehat{E}_{t} \pi_{t+1}+\varepsilon_{t}^{b}\right) \\
y_{t} & =\Phi_{p}\left(\alpha k_{t}^{s}+(1-\alpha) l_{t}+\varepsilon_{t}^{a}\right) \\
k_{t}^{s} & =k_{t-1}+u_{t} \\
u_{t} & =u_{1} r_{t}^{k} \\
k_{t} & =k_{1} k_{t-1}+\left(1-k_{1}\right) i_{t}+k_{2} \varepsilon_{t}^{i} \\
\mu_{t}^{p} & =\alpha\left(k_{t}^{s}-l_{t}\right)+\varepsilon_{t}^{a}-w_{t} \\
\pi_{t} & =\pi_{1} \pi_{t-1}+\pi_{2} \widehat{E}_{t} \pi_{t+1}-\pi_{3} \mu_{t}^{p}+\varepsilon_{t}^{p} \\
r_{t}^{k} & =-\left(k_{t}-l_{t}\right)+w_{t} \\
\mu_{t}^{w} & =w_{t}-\left(\sigma_{l} l_{t}+\frac{1}{1-h / \gamma}\left(c_{t}-\frac{h}{\gamma} c_{t-1}\right)\right) \\
w_{t} & =w_{1} w_{t-1}+\left(1-w_{1}\right) \widehat{E}_{t}\left(w_{t+1}+\pi_{t+1}\right)-w_{2} \pi_{t}+w_{3} \pi_{t-1}-w_{4} \mu_{t}^{w}+\varepsilon_{t}^{w} \\
r_{t} & =\rho_{r} r_{t-1}+\left(1-\rho_{r}\right)\left[\chi_{\pi} \pi_{t}+\chi_{y}\left(y_{t}-\Phi_{p} \varepsilon_{t}^{a}\right)\right]+\varepsilon_{t}^{r}
\end{aligned}
$$

\footnotetext{
${ }^{3}$ The reader is referred to the extensive appendix in Smets and Wouters (2007) for a step-by-step derivation of these equations.
} 
The composite coefficients are given by:

$$
\begin{array}{lll}
c_{y}=1-i_{y}-g_{y} ; & i_{y}=\delta k_{y} ; & u_{y}=r_{k}^{*} k_{y} ; \\
c_{1}=h /(1+h) ; & c_{2}=\left(\sigma_{c}-1\right)\left(W_{*}^{h} L_{*} / C_{*}\right) / \sigma_{c}(1+h) ; & c_{3}=(1-h) /\left[\sigma_{c}(1+h)\right] ; \\
i_{1}=1 /(1+\beta) ; & i_{2}=1 /[(1+\beta) \varphi] ; & \\
q_{1}=\beta(1-\delta) ; & & \\
z_{1}=\psi /(1+\psi) ; & & \\
k_{1}=1-\delta ; & k_{2}=\delta(1+\beta) \varphi ; & \\
\pi_{1}=\iota_{p} /\left(1+\beta \iota_{p}\right) ; & \pi_{2}=\beta /\left(1+\beta \iota_{p}\right) ; & \\
\pi_{3}=\left[1 /\left(1+\beta \iota_{p}\right)\right]\left[\left(1-\beta \xi_{p}\right)\left(1-\xi_{p}\right) /\left(\xi_{p}\left(\phi_{p}-1\right) \varepsilon_{p}+1\right)\right] ; & \\
w_{1}=1 /(1+\beta) ; \quad w_{2}=\left(1+\beta \iota_{w}\right) /(1+\beta) ; & w_{3}=\iota_{w} /(1+\beta) ; \\
w_{4}=[1 /(1+\beta)]\left[\left(1-\beta \xi_{w}\right)\left(1-\xi_{w}\right) /\left(\xi_{w}\left(\phi_{w}-1\right) \varepsilon_{w}+1\right)\right] . &
\end{array}
$$

Equation (2.1) is the economy's aggregate resource constraint: output is denoted by $y_{t}$, consumption by $c_{t}$, investment by $i_{t}$, and variable capacity utilization by $u_{t}$. The term $\varepsilon_{t}^{g}$ denotes an exogenous government spending shock. The coefficients $c_{y}, i_{y}$, and $u_{y}$, denote the steady-state shares of consumption, investment, and resources used to vary capital utilization, expressed as a fraction of steady-state output.

Equation (2.2) is the Euler equation for consumption. Consumption depends on expected future consumption, on past consumption, through the assumption of habit formation in households' preferences, on current and expected hours of work $l_{t}$, on the ex-ante real interest rate $\left(r_{t}-\right.$ $E_{t} \pi_{t+1}$, and on a risk-premium shock $\varepsilon_{t}^{b}$. It is perhaps more common in the macro literature to assume a preference shock with the power of shifting the Euler equation; the risk-premium shock has similar implications, but with the advantage of helping the model match the comovement between consumption and investment by entering also in (2.4). The main coefficients of interest in this equation are $h$, the degree of habit formation in consumption, and $\sigma_{c}$, the inverse of the intertemporal elasticity of substitution in consumption.

Equation (2.3) represents the first-order condition for investment. Current investment depends on lagged and expected investment, and on the value of capital stock $q_{t}$. The term $\varepsilon_{t}^{i}$ represents a disturbance that accounts for investment-specific technological change. The dynamics of the value of capital $q_{t}$ is characterized by equation (2.4): it depends on its future expected value, on expectations about the rental rate on capital $E_{t} r_{t+1}^{k}$, and on the ex-ante real interest rate, adjusted for the risk-premium disturbance. The elasticity of investment to $q$ is governed by the coefficient $\varphi$, which represents adjustment costs in investment.

Equation (2.5) denotes a Cobb-Douglas aggregate production function: the technology to produce output requires capital services $k_{t}^{s}$ and labor hours, which enter with shares $\alpha$ and $(1-\alpha)$. The term $\varepsilon_{t}^{a}$ denotes the neutral technology shock, while the coefficient $\Phi_{p}$ accounts for the existence of fixed costs in production. The model assumes variable capital utilization. As equation (2.6) shows, capital services used to produce output are, therefore, a function of the whole capital stock 
in the previous period (given the assumption that capital becomes effective after a one-quarter lag) and the capital utilization rate $u_{t}$. The degree of capital utilization is varied depending on the rental rate of capital (equation (2.7)); the relation depends on the parameter $0 \leq \psi \leq 1$, which is a positive function of the elasticity of the capital adjustment cost function, but normalized to be between 0 and 1 .

The capital accumulation equation (2.8) shows that capital, net of depreciation, changes due to new investment and to the efficiency of these new investments, captured by the investment-specific technology process $\varepsilon_{t}^{i}$.

Equations (2.9) and (2.10) summarize the equilibrium in the goods market. Inflation $\pi_{t}$ is a function of both lagged and expected inflation, and it depends on the time-varying price mark-up $\mu_{t}^{p}$ and on the price mark-up shock $\varepsilon_{t}^{p}$. The price mark-up $\mu_{t}^{p}$ equals the difference between the marginal product of labor $\left(\alpha\left(k_{t}^{s}-l_{t}\right)+\varepsilon_{t}^{a}\right)$ and the real wage $w_{t}$.

Equation (2.11) shows that the rental rate of capital is a function of the capital to labor ratio and of the real wage.

Equations (2.12) and (2.13) describe the labor market. The wage mark-up $\mu_{t}^{w}$ captures the difference between the real wage and the marginal rate of substitution between consumption and leisure, given by $\left(\sigma_{l} l_{t}+\frac{1}{1-h}\left(c_{t}-h c_{t-1}\right)\right)$, where $\sigma_{l}$ is the inverse of the Frisch elasticity of labor supply. The real wage depends on its past and expected future values, on current, past, and expected inflation, and on the wage mark-up. Wage dynamics is also affected by the wage mark-up disturbance $\varepsilon_{t}^{w}$. The importance of the backward-looking terms in the inflation and wage equations are driven by the indexation to past inflation coefficients $\iota_{p}$ and $\iota_{w}$; the slopes of the curves are an inverse function of the Calvo price and wage stickiness coefficients $\xi_{p}$ and $\xi_{w}$.

Finally, equation (2.14) serves as an approximation of monetary policy decisions in the economy. The monetary authority follows a Taylor rule with partial adjustment, moving the short-term nominal interest rate $r_{t}$ in response to changes in inflation and the output gap. The Taylor rule is simplified with respect to the one used in Smets and Wouters (2007). Potential output is not defined here as the level of output in the same economy, but under flexible prices. Given that the estimation is complicated by the addition of sentiment shocks, learning, and so forth, I avoid augmenting the state-space with extra equations for the flexible price economy: the output gap is simply defined here as the deviation of output from a potential level of output driven exclusively by technology. 
All exogenous shocks, except the monetary policy shock, which is i.i.d., are assumed to evolve as AR processes as in Smets and Wouters (2007). ${ }^{4}$ The government spending shock is allowed to respond to innovations in technology as $\varepsilon_{t}^{g}=\rho_{g} \varepsilon_{t-1}^{g}+\tilde{\varepsilon}_{t}^{g}+\rho_{g a} \tilde{\varepsilon}_{t}^{a}$, where $\tilde{\varepsilon}_{t}^{g}$ and $\tilde{\varepsilon}_{t}^{a}$ are spending and technology innovations and $\rho_{g a}$ is a coefficient to be estimated.

Therefore, the model summarizes the dynamics for fourteen endogenous variables. Smets and Wouters (2007) use observables for seven of the variables. Moreover, there are seven structural disturbances that are unobserved and are obtained by filtering. To the observables and shocks in Smets and Wouters (2007), I will add available observable data on expectations about consumption, investment, and inflation, and expectational, or sentiment, shocks, which are defined in the next section.

\section{Relaxing Rational Expectations: Learning and Sentiment}

Economic agents in the model form expectations about future aggregate consumption, investment, hours of work, inflation, real wages, the rental rate of capital, and the value of capital. The literature typically assumes that such expectations are formed according the rational expectations hypothesis. Here, we relax the strong informational assumptions imposed by rational expectations to exploit direct, observed, data on expectations, and to investigate the role of sentiment on the economy.

Agents are assumed to form expectations using their perceived model of the economy, which is correctly specified, i.e., it has the same structural form as the minimum state variable (MSV) solution under rational expectations. The departure from rational expectations consists of agents' lacking knowledge about the reduced-form model coefficients (for example, they lack knowledge about Calvo coefficients and, as a result, they cannot recover the reduced-form coefficients in the model solution of the system) and of the realizations of the unobserved structural disturbances. ${ }^{5}$ Therefore, while the model departs from rational expectations, the departure is usually interpreted as a 'minimal' deviation and the model can be defined as near-rational.

Economic agents use historical data to infer the unknown coefficients over time. They do so by estimating the following perceived law of motion

$$
Y_{t}=a_{t}+b_{t} Y_{t-1}+\epsilon_{t}
$$

\footnotetext{
${ }^{4}$ Smets and Wouters (2007) assume MA(1) components in the price and wage markup shocks. We assume that they also follow AR processes here.

${ }^{5}$ Chung and Xiao (2013) discuss how the assumption that agents cannot observe fundamental shocks is needed to satisfy the guiding principle of "cognitive consistency" in the adaptive learning literature, i.e., the principle that agents in the model should not be endowed with more information than econometricians have available when working with the model.
} 
where $Y_{t}=\left[c_{t}, i_{t}, q_{t}, l_{t}, k_{t}, r_{t}^{k}, \pi_{t}, w_{t}, r_{t}\right]^{\prime}$, and $a_{t}$ and $b_{t}$ are vectors and matrices of coefficients. Restrictions with ones and zeros on the coefficients are used to select variables that do or do not enter the MSV solution $\left(q_{t}, l_{t}\right.$, and $r_{t}^{k}$ do not enter the model in lags and, hence, the corresponding coefficients on their lagged values in $b_{t}$ equal 0). ${ }^{6}$ Agents use data on the endogenous variables to form expectations, but they do not observe the structural disturbances that would also enter the PLM, but that are typically unobserved to the econometrician. Besides cognitive consistency, I regard this as the most empirically realistic description of the information available to forecasters.

In each period $t$, agents are assumed to observe values of the endogenous variables up to $t-1$. This assumption is mainly motivated by the need to be consistent with the timing in the Survey of Professional Forecasters: when survey participants are asked in period $t$ for their forecasts for period $t+1$, they can observe historical data only up to $t-1$. The assumption is also typical in the theoretical learning literature as a means to avoid simultaneity issues in self-referential models. Therefore, agents, in each period $t$, form expectations using observations up to $t-1$ along with their beliefs, which they have previously updated by running regressions of $(t-1)$-dated variables on $(t-2)$-dated variables.

The beliefs are recursively updated following a constant-gain learning algorithm as

$$
\begin{aligned}
\widehat{\phi}_{t} & =\widehat{\phi}_{t-1}+\overline{\mathbf{g}} R_{t}^{-1} X_{t}\left(Y_{t}-\widehat{\phi}_{t-1}{ }^{\prime} X_{t}\right)^{\prime} \\
R_{t} & =R_{t-1}+\overline{\mathbf{g}}\left(X_{t} X_{t}^{\prime}-R_{t-1}\right)
\end{aligned}
$$

where $X_{t} \equiv\left[1, Y_{t-1}\right]^{\prime}$, and $\widehat{\phi}_{t}=\left[a_{t}, b_{t}\right]^{\prime}$. Equation (3.2) describes the updating of beliefs regarding the model solution coefficients, while equation (3.3) describes the updating of the corresponding precision matrix $R_{t}$.

Given knowledge of the endogenous variables in $(t-1)$ and given the state of recently updated beliefs, observed expectations are assumed to be formed as follows

$$
\widehat{E}_{t-1} Y_{t+1}=\left(I+\widehat{b}_{t-1}\right) \widehat{a}_{t-1}+\widehat{b}_{t-1}^{2} Y_{t-1}+\widehat{d} \alpha_{t}
$$

where $\alpha_{t}$ is the vector collecting the different sentiment shocks $\alpha_{t}=\left[\alpha_{t}^{c}, \alpha_{t}^{i}, \alpha_{t}^{\pi}\right]^{\prime}$, and $d$ is a selection matrix with elements equal to 1 for expectations for which an observable is available and 0 otherwise.

Expectations can, therefore, be decomposed in two parts. One consists of the endogenous reaction of expectations to the state of the economy, given the agents' learning beliefs: this is the forecast implied by the near-rational learning model (i.e., the right-hand side except $d \alpha_{t}$ ). The other consists

\footnotetext{
${ }^{6}$ No restrictions are imposed on the variance-covariance matrix of $\epsilon_{t}$.
} 
of the component of expectations that cannot be rationalized as derived as the outcome of a nearrational model. This second component accounts for exogenous movements in expectations that are unrelated to observed fundamentals.

Expectations in the model about consumption, investment, and inflation, will be matched to the corresponding observable expectation variables in the empirical analysis. Those observed expectations are assumed to be formed from the near-rational learning model specified above. But in each period, agents are allowed to deviate from the point forecasts that arise from their nearrational model: they can form forecasts that are unduly optimistic or pessimistic, given the state of the economy and their most recent updated beliefs. These deviations, which are the component of expectations that cannot be explained as the outcome of the near-rational learning model, are defined as "sentiment" in the model. Sentiment, therefore, captures exogenous waves of optimism and pessimism, which cannot be explained by existing economic conditions. ${ }^{7}$

\section{Sentiment and the Business Cycle: Estimation Approach}

4.1. Observed Expectations and Real-Time Data. The model is estimated using Bayesian methods to match the following set of observables: Real GDP, Real Consumption, Real Investment, Hours worked, Real Wage, Inflation, Federal Funds rate, Expected Real Consumption, Expected Real Investment, and Expected Inflation. Therefore, to extract and investigate the role of sentiment shocks, I add to the same variables that are used in Smets and Wouters (2007) information on expectations about future consumption, investment, and inflation (I do not exploit forecasts on output and interest rates as these variables don't enter the model in expectations). ${ }^{8}$ The structural "deep" parameters, the shock parameters, the learning, and sentiment, parameters will all be jointly estimated.

The data on expectations are obtained from the Survey of Professional Forecasters (SPF), hosted by the Federal Reserve Bank of Philadelphia. I use the mean of expectations across forecasters for levels of consumption, investment, and for the inflation rate. In each period $t$, agents in the model, in the same way as forecasters in the survey, form expectations about variables in $t+1$, knowing the values of endogenous variables up to $t-1$ (forecasters at each $t$ are also asked for their estimate of variables in $t-1$ and the vast majority of them simply reports the latest BEA data release for variables in $t-1)$. In the $\mathrm{SPF}$, the forecasts that will be used in the empirical analysis correspond to the column ' $d$ Variable3', i.e., expectations about values of the variable one-quarter-ahead.

\footnotetext{
${ }^{7}$ For variables for which a corresponding observable series is not available, the expectations in the empirical analysis will be simply equal to those implied by the learning model.

${ }^{8}$ In principle, they could still be used in the estimation, but this is not the approach that I follow here.
} 
Expectations about consumption correspond to the series "Forecasts for the quarterly and annual level of real personal consumption expenditures (RCONSUM)". Expectations about investment are obtained by adding the series for nonresidential and residential investment: "Forecasts for the quarterly and annual level of real nonresidential fixed investment (RNRESIN)" and "Forecasts for the quarterly and annual level of real residential fixed investment (RRESINV". These forecasts are available starting from 1981:Q3, which is, therefore, chosen as the sample starting date for the main estimation in the paper. Expectations about inflation are calculated from the price level series "Forecasts for the quarterly and annual level of the GDP Price Index (PGDP)"; the series is available from 1968:Q3. The series have been transformed to maintain the same base year across the full sample.

Given the focus on identifying the learning process of economic agents in real-time and on disentangling the components of expectations that can be rationalized as the outcome of a learning model or attributed to exogenous sentiment, it is important that the estimation captures as closely as possible the information set available to agents at each point in the sample. For this reason, I choose to use real-time data in the estimation.

For each variable being forecasted, the SPF provides a link to "Real-time data for this variable". I use those to better approximate the information set available to forecasters in real time and as the observable series in the model. The realized data series for each variable are hence obtained from the corresponding Real Time Data Set for Macroeconomists' website, also hosted by the Federal Reserve of Philadelphia, with the exception of the Federal Funds rate (which is not subject to revision), which is obtained from the FRED database, made available by the Federal Reserve of St. Louis.

For consumption, investment, and inflation, therefore, I use the real-time data series corresponding to the forecasts described above. I use the real-time real GDP series (ROUTPUT) as measure of output. Hours are computed using the total aggregate weekly hours index $(\mathrm{H})$ divided by civilian noninstitutional population (POP). I compute real wages as total wage and salary disbursements, private industries (WSD), divided by total aggregate hours and by the GDP deflator. The definition for wages is somewhat different from the one used in Smets and Wouters (2007). I choose to use a related definition, for which real-time data are available, rather than the same series they use, but for which real-time data do not exist. Finally, as measure of the short-term nominal interest rate, I use the Federal Funds rate (FEDFUNDS) from FRED. The annual series is converted into quarterly rates for the estimation. 
The estimation sample spans the years from 1981:III to 2011:I; the starting date is chosen due to the availability of expectations data (available only from 1981:III for consumption and investment expectations). All variables are at quarterly frequency. The raw variables, before any detrending, that will be used in the estimation are shown in Figure 1.

4.2. Trends and State-Space System. I present the state-space system for the model in its more general form, with the variables in levels, rather than in detrended or growth rate form. The estimation on raw data is in the spirit of Canova (2012) and Canova and Ferroni (2011), and it permits to evaluate different detrending procedures.

The state space system can be written as:

$$
\begin{aligned}
Y_{t}^{O B S} & =\bar{H}+H\left(T_{t}+\xi_{t}\right) \\
\xi_{t} & =A_{t}+F_{t} \xi_{t-1}+G \omega_{t}
\end{aligned}
$$

where $\xi_{t}=\left[Y_{t}, \widehat{E}_{t} Y_{t+1}, \varepsilon_{t}, \alpha_{t}\right]^{\prime}, \omega_{t} \sim N\left(0, \sigma_{\omega}^{2}\right)$.

Equation (4.1) is the measurement equation that relates observed data series to the variables in the model and it separates between noncyclical, or trend, $\left(T_{t}\right)$, and cyclical components $\left(\xi_{t}\right)$. The vector $\bar{H}$ may contain steady state parameters or simply the sample mean of the variables, and the matrix $H$ selects variables for which observables are available from the state vector.

Equation (4.2), instead, represents the DSGE model for the cyclical components of the series. Under rational expectations, the equation corresponds to the rational expectation solution of the system (2.1)-(2.14), which has constant coefficients $A_{t}=A=0$ and $F_{t}=F$. With observed expectations and learning, it is obtained by replacing rational expectations with survey expectations, and allowing survey expectations to derive from the near-rational learning model as in (3.4). The vectors and matrices of coefficients are possibly time-varying as a result of agent's learning process, as modeled in (3.2)-(3.3).

I consider two detrending options. The first is a linear trend, which can be expressed as $T_{t}=$ $\delta_{0}+\delta_{1} t$. Besides its simplicity, an advantage of the linear trend is that it is probably more likely than more sophisticated alternatives to mimic the trend and cycle decomposition that forecasters had in mind when communicating their survey forecasts over the sample. An extension of the linear trend specification, intended to even better capture the trend estimation by forecasters in real time, consists of adopting a recursive linear trend. In this case, the trend coefficients $\delta_{0}$ and $\delta_{1}$ are estimated using only information from $t=1$ up to $t=\tau$, at each point $\tau$ in the sample. In line with the spirit of the learning approach, when forming expectations, agents also learn about 
the trend, and use the trend coefficient they have estimated on time series available up to $t-1$ to forecast variables in $t+1$. This is the second approach that will be considered in the estimation.

I allow the trends to differ across each variable. ${ }^{9}$ Also to minimize a priori assumptions, I allow trends to potentially matter for each observable variable, including inflation and the interest rate (which actually display declining trends over the sample, but are often treated as stationary in DSGE estimations). Expectation series are also detrended, and their trends are allowed to differ from those of the corresponding realized variables (but whether the trends differ from or match with those of the realized variables has been found to be uninfluential for the results).

4.3. Bayesian Estimation and Priors. The priors for the model coefficients are shown in Table 1. The majority of prior choices follow Smets and Wouters (2007). There are, however, some differences. The prior for the intertemporal elasticity of substitution is a Gamma with mean 2 and standard deviation 0.5 . The degree of habit formation has prior mean 0.5 , rather than the higher 0.7 used by Smets and Wouters. The priors for the Calvo coefficients here are Beta with mean 0.7, rather than 0.5 , to be more consistent with the recent micro-level evidence on price stickiness (Nakamura and Steinsson, 2008). The shock autoregressive coefficients all follow Beta prior distributions with means equal to 0.5 and standard deviations 0.2. Inverse Gamma distributions are used for shock standard deviations: they have prior means equal to 0.3 in all cases, except the shocks related to investment, which have a mean of 1 , given the a priori expectation that exogenous shifts in investment efficiency may have higher volatility. For the main learning parameter, I assume a Beta prior with mean 0.025 and standard deviation 0.01 , which spans the range of calibrated constant gain parameters used in the theoretical adaptive learning literature.

The model is estimated using full-information Bayesian techniques. Draws are generated using the Metropolis-Hastings algorithm. I run 400,000 draws, discarding the initial $40 \%$ as burn-in. The parameter posterior distributions are usually well-behaved. When bimodality exists, I will point it out in the discussion of the results.

4.4. Initialization of the Agents' Learning Process. Besides detrending details, another factor that may potentially affect the results is the initialization of the agents' learning process. Again,

\footnotetext{
${ }^{9}$ I have also performed the estimation for the case in which the restriction that a common trend exists among real variables is imposed, to allow for a balanced growth path. I have chosen to relax this restriction here (and, therefore, I do not explicitly include growth around a balanced growth path), since the fit becomes substantially worse than the variable-specific trend assumption. The assumption of a common trend among real variables is even more strongly rejected with real-time, than revised final-vintage data. Therefore, I prefer to use a more empiricallyoriented specification, which fits the data better, than a 'more rigorous' theoretical specification, which fits the data very poorly and might lead to spurious conclusions.
} 
I consider two alternatives. The preferred initialization can again be chosen on the basis of its ability to fit the data; moreover, I will show later in the paper that the empirical conclusions are robust to different choices of initial beliefs at the beginning of the sample.

To avoid imposing arbitrary assumptions about initial values on the main estimation results, I first estimate the model for a presample period. The initialization requires full-information Bayesian estimation, since also some unobservable variables, which need to be obtained by filtering, enter the MSV solution. The model is therefore estimated on the 1964:I-1981:II sample (with initial date chosen since labor hours are available from 1964). I consider the results under two main options (I also considered other closely-related alternatives, without effects on the results).

4.4.1. REE from 1964-1981 pre-sample. In the first, I estimate the model in the presample period under the assumption of rational expectations. Under this approach, when moving to the main estimation on the second sample (1981-2011), I set the initial beliefs as equal to their rational expectations equilibrium obtained from the presample period, i.e. $\widehat{\phi}_{t=0}=\widehat{\phi}_{R E}$. The precision matrix is similarly initialized as $R_{t=0}=X X_{R E}^{\prime}$, which is also the value obtained in the presample estimation under rational expectations. Both $\phi_{t=0}$ and $R_{t=0}$ are obtained as means across $\mathrm{MH}$ draws, after a burn-in period, in the rational expectations DSGE estimation. The interpretation of this initialization is as follows: agents living in the 1964-1981 period are assumed to have had enough time to converge to the rational expectations equilibrium. The post-1981 sample may be interpreted as a new regime: agents start from their beliefs that they have formed by living in the pre-1981 regime and gradually learn about the new structure of the economy in the second sample. ${ }^{10}$

4.4.2. Ending Point of Learning Beliefs from 1964-1981 pre-sample. The second option is more agnostic. I estimate also the model in the presample 1964-1981 period under non-fully rational expectations and learning. The initialization in 1964 is left as uninformative as possible: all variables in the perceived law of motion are assumed to evolve as $\operatorname{AR}(1)$ with an autoregressive coefficient equal to 0.9. This choice assigns agents the knowledge that macroeconomic variables are persistent, but it doesn't endow them with information on more complicated dynamic interactions among variables. The learning process is, therefore, given time to update in the presample estimation, and the state of beliefs at the end of the presample (1981:III) is then set as the initial set of beliefs for the main post-1981 estimation. The 70 quarterly periods in the presample estimation provide sufficient time to remove the most severe effects of initial conditions.

\footnotetext{
${ }^{10}$ We do not follow the practice of starting from RE estimates, since those require estimation over the full sample, which cannot be in the agents' information set in 1964 .
} 
The benchmark results described in the next section will refer to the estimated model version that delivers the highest marginal likelihood (i.e., the case with linear detrending and initial beliefs derived from presample estimation under learning). Posterior estimates and other results for the full set of estimated specifications will discussed in the robustness section.

\section{Sentiment and the Business Cycle: Empirical Results}

5.1. Business Cycle Evidence under Rational Expectations. For the sake of comparison, I start by estimating the model under the conventional assumption of rational expectations. Agents have perfect knowledge regarding the model parameters, other agents' preferences and constraints, the distribution of the shocks, and so forth. Expectational errors in this scenario (given that the equilibrium exists and is unique) are simply a function of structural innovations and do not represent an autonomous source of fluctuations in the model.

The estimation under rational expectations is similar to the one in Smets and Wouters (2007), but with the difference that here I use real-time data, rather than revised data. Moreover, I consider a different detrending procedure, the sample is limited to the post-1981 period and extended to 2011, and some series definitions differ, given the need here to match the real-time series on realized variables and their forecasts (for example, the wage series is different form the one in Smets and Wouters). There are some minor differences in priors and model specifications.

The parameters estimated for the DSGE model under rational expectations are shown in Table 1. The estimation reveals significant degrees of real frictions, such as investment adjustment costs (with a posterior estimate for $\varphi=5.96$, which updates the prior toward larger values) and habit formation in consumption $(h=0.70)$, which are necessary to fit the sluggishness of macroeconomic data. Nominal rigidities are also essential: the posterior mean estimate for the Calvo coefficient in price-setting falls on the high side at 0.88, probably as a result of a less restrictive prior (while Smets and Wouters impose a prior with mean 0.5, I allow let here the data free to move to regions with higher price stickiness), and for the Calvo wage-stickiness coefficient is equal to 0.80. Indexation to past inflation is important in wage-setting $\left(\iota_{w}=0.58\right)$, but less so in price-setting $\left(\iota_{p}=0.14\right)$.

Structural disturbances related to government spending and technology are very persistent, with autoregressive coefficients above 0.9. The investment-specific technology shock and the price markup shock are also persistent with autoregressive coefficients equal to 0.68 and 0.73 . The wage markup shock has only a limited serial correlation, a result that differs from the corresponding estimate in Smets and Wouters and that is in large part due to the choice of relaxing the assumption of a common trend between the real wage and other real variables. The posterior mean for 
the autocorrelation of the risk-premium disturbance is quite low (0.23). The estimation, however, reveals a clear bimodality: one mode is characterized by a very large degree of habit formation in consumption, but a low serial correlation of the exogenous risk-premium shock, the other by a more moderate degree of habit formation, but by a substantially serially-correlated risk premium. Bivariate posterior scatter plots indicate a strong negative relation between the two coefficients. The high habits-low autocorrelation mode, however, achieves higher probability and is, therefore, visited much more often by the MCMC sampler.

Figures 2 and 3 show the impulse responses of output and inflation to selected shocks. Many impulse responses show the usual hump-shaped patterns. Output responds sluggishly to investmentspecific, technology, wage markup, and monetary policy shocks. The peak effect for the riskpremium shock happens two quarters after the initial impact, whereas peaks are more delayed for the previous shocks, ranging from four quarters for the investment-specific to eight/ten quarters for the technology and wage markup shocks. Inflation adjusts somewhat more quickly to the shocks.

The variance decomposition for the model with rational expectations is shown in Table 2 (the shares for rational expectations are those shown in brackets under the shares for the learning and sentiment model that will be discussed later).

The shock that is responsible for the largest portion of fluctuations is the investment-specific shock, which is the dominant shock at high frequencies, explaining $63 \%$ of output variability at horizons below one year, and it is also important at business-cycle frequencies, with a share of the forecast error variance for output of $38.7 \%$; a predominant role for this shock has been found also in Justiniano et al. (2010). Technology shocks are the main contributors at business-cycle horizons: in addition to the investment-specific shock, the Hicks-neutral technology shock accounts for another $40 \%$ of fluctuations.

The variance of inflation is mostly driven by the price markup shock at high frequencies, and by investment-specific shocks at lower frequencies, with technology, price, and wage markup shocks also playing a major role.

5.2. Learning and Sentiment. I now move to estimate the version of the model that relaxes the stringent informational assumptions imposed by rational expectations. Economic agents form subjective expectation from a near-rational model and can deviate from near-rational forecasts because of exogenous changes in "sentiment". Observed expectations are used to better identify the economic agents' learning process over the sample and the expectation components that can be attributed to sentiment. 
Table 1 shows the posterior estimates for the best-fitting version, which is the one with simple linear detrending and initial agents' beliefs set in 1981 to match those obtained from the presample estimation under learning. To gauge the sensitivity of results to the various assumptions, I will present the estimates for the alternative detrending and learning initialization, along with other sensitivity checks, later in Table 3 .

It can be noticed that the near-rational learning model provides a successful approximation of how survey forecasters form expectations in real-time. Figure 4 displays the survey-based expectations, along with the implied expectations from the near-rational learning model, which represent the endogenous component of expectations, excluding sentiment, in (3.4). The learning expectations track observed survey forecasts relatively closely for most of the sample, with few episodes of divergence between the two. Given that sentiment is identified in the estimation as the part of expectations that cannot be explained by the near-rational learning model, these results reassure us that an important role for sentiment is not likely to arise from a severe misspecification of the agents' forecasting model.

There are three areas in which the results under learning and sentiment provide insights that go beyond traditional results under rational expectations: the role of real frictions, or of the socalled "mechanical" sources of persistence, the response of macroeconomic variables to structural innovations, and the sources of business cycles.

5.2.1. Mechanical sources of persistence. When direct data on expectations are used to replace rational expectations, the estimation points toward smaller degrees of real frictions that are necessary to fit the persistence in the data. In particular, the posterior mean for the elasticity of the investment adjustment cost function is considerably reduced from $\varphi=5.96$ under rational expectations to $\varphi=2.67$ with observed expectations and learning. The lower magnitude of adjustment costs removes some of the delays and sluggishness in the responses of output and investment to shocks. The estimated degree of habit formation in consumption $h$ also falls from 0.70 to 0.48 .

The intermediate level of habit formation obtained in the estimation with subjective expectations and learning is mostly due to the estimation's attempt to close the non-separability between consumption and leisure (by concurrently moving $\sigma_{c}$ closer to 1) and, at the same time, to lower the sensitivity of consumption to the ex-ante real interest rate (by raising the estimated degree of habit formation). Therefore, I re-estimate the model with separable preferences between consumption and leisure to assess the role of this channel. The posterior estimates show that the degree of habit formation becomes lower (0.34 rather than 0.70 as under rational expectations). 
Turning to nominal rigidities, the level of price stickiness remains similar between rational and subjective expectations estimations, whereas the estimated wage stickiness is reduced to 0.71 , indicating wages that are re-optimized on average every ten months. Wage indexation to past inflation is moderately lower under subjective expectations.

The mean estimates for the elasticity of labor supply vary between rational expectations and learning, but, as indicated by the wide $95 \%$ credible sets, the uncertainty surrounding their estimation is substantial. A key parameter in models with learning is the constant gain: here the gain is estimated equal to 0.013 , suggesting that learning by economic agents takes place rather slowly. ${ }^{11}$

One of the main differences in terms of estimation results concerns the properties of some of the shocks: the estimated persistence for the investment-specific shock is reduced from 0.68 to 0.14 and for the price markup shock falls from 0.73 to 0.09. The risk-premium shock is close to i.i.d., with an autoregressive coefficient equal to 0.10. Sentiment shocks are, instead, identified as quite persistent with autocorrelations in the 0.7-0.85 range.

The estimation results are suggestive that subjective expectations and learning help in capturing some of the persistence in macroeconomic data. Figure 5 helps in summarizing the evidence. The figure shows posterior distributions for selected endogenous and exogenous sources of persistence. The first panel compares the posterior distributions for the investment adjustment cost coefficient obtained for the model under rational expectations and under learning. The second panel overlaps the posterior distributions for the autoregressive coefficient related to the investment-specific technology disturbance, both under rational expectations and learning. Given that endogenous and exogenous sources of persistence can be interchangeable for some variables, the third and fourth panels show the posterior distributions for the sum of the coefficients capturing the endogenous mechanism and the autoregressive coefficient for the exogenous shock, instead of distributions for single coefficients. The third panel refers to sources of persistence in consumption (habits plus the serial correlation of the risk-premium disturbance) and the fourth to sources of persistence in inflation (endogenous indexation to past inflation plus serial correlation in the price markup shock). The posterior distributions indicate that large degrees of structural and exogenous persistence are needed to fit the data under the assumption of rational expectations. If rational expectations are replaced by observed expectations in a model with learning, there is less need for additional sources of persistence: the relevant posterior distributions all markedly shift to the left.

\footnotetext{
${ }^{11} \mathrm{~A}$ constant gain equal to 0.013 means that agents weigh the current observation as 1 , the $t-1$ observation as 0.987 , the $t-2$ observation as $0.987^{2}$, and so forth.
} 
5.2.2. Responses to structural and sentiment shocks. Figures 6 and 7 overlap the responses of output and inflation to some of the most influential structural and sentiment disturbances (given that impulse responses are time-varying under learning, to simplify the presentation in the graph, I report average impulse responses over the sample). The figures show the mean impulse responses across the last 50,000 MCMC draws, along with error bands corresponding to the 5th and 95th percentiles.

The first set of impulse responses shows that output responds rather quickly to structural innovations. The response to the government spending and risk premium shocks reach their peak effects on impact, while the investment-specific shock generates a peak after only one quarter. Particularly for the case of the risk-premium and investment-specific shocks, the effects are transmitted more quickly to the economy in the estimation that uses subjective rather than rational expectations.

Sentiment shocks, instead, produce longer adjustments. The sentiment shock related to investment leads to a larger and more persistent response of output compared with the corresponding investment-specific structural shock. The output response is hump-shaped with stronger effects between one and two years after the initial impact. The magnitude of the effect for the consumption sentiment shock is roughly similar to the magnitude for the risk-premium shock, except for shorthorizons, where the risk-premium dominates. Both sentiment shocks lead to sluggish adjustment in output with more forceful effects that are delayed by at least one year.

Figure 7 displays the impulse response functions for inflation. The top panel shows the responses to the cost-push (price-markup and wage-markup) and inflationary sentiment shocks. The bottom panel shows the responses to the neutral and investment-specific technology shocks and to the two demand-related sentiment shocks. The price markup shock leads to a large immediate response in inflation, but the adjustment is very quick. Fluctuations in inflation over the medium term are mostly driven by sentiment about future inflation pressures, with the wage markup shock playing a role at longer horizons. Technology shocks lead to a negative sluggish response in inflation. Sentiment about aggregate demand, however, plays an even more important role over the business cycle by producing persistent adjustments in inflation.

5.2.3. Sources of Business Cycles. What are the main drivers of business cycle fluctuations? The literature is divided between explanations focused on technology shocks and explanations based on demand shocks. On the other hand, shifts in expectations that are unrelated to fundamentals, psychological forces and market sentiment, waves of optimism and pessimism, typically receive a zero weight as drivers of fluctuations in state-of-the-art general equilibrium macroeconomic models. 
By relaxing the assumption of rational expectations and using data on observed expectations, this paper can test the contribution of sentiment to aggregate fluctuations.

Table 2 shows the forecast error variance decomposition for short-run (here 0 to 4 quarters) and business cycle frequencies (here 4 to 24 quarters, but results were similar for a definition based on 6 to 32 quarters).

Sentiment shifts are indeed a major contributor of business cycle fluctuations. The ensemble of sentiment shocks explains $44 \%$ of output fluctuations. The most important driver of output fluctuations at business cycle frequencies appears to be the sentiment shock related to investment expectations, which accounts by itself for $35 \%$ of the variance. The structural investment-specific technology shock is dominant, among the remaining shocks, accounting for $19 \%$ of fluctuations. The key role of sentiment linked to investment decisions is clearly reminiscent of Keynes' animal spirits, which he also discussed in relation to entrepreneurs' investment behavior. Sentiment shocks explain more than $60 \%$ of the variability of investment and $40 \%$ of the variability in consumption.

Inflation is also largely driven by sentiment shifts. Inflation sentiment is dominant over business cycle horizons, accounting for almost $60 \%$ of the inflation forecast error variance.

While sentiment shocks are particularly important at business cycle frequencies, they also play a role in creating noise at higher frequencies. Sentiment explains between $21 \%$ and $35 \%$ of short-run fluctuations in the same variables, with investors' sentiment again playing the largest role, among the sentiment shocks, for movements in output. Consumers' sentiment also matters, accounting for a third of aggregate consumption variability in the short-run. Some of the structural shocks have become less persistent in the model with observed expectations. As a result, they are mostly important at horizons below one year: the risk premium shock is the main determinant of shortrun consumption movements, the investment-specific shock is the main determinant of short-run investment, and the price markup shock is the main determinant of short-run inflation. Government spending and investment-specific innovations are the main drivers of output variability at horizons below one year.

The empirical results seem to suggest that structural shocks are important, but they have a large and immediate impact on the economy, rather than a prolonged one. At business cycle frequencies, sentiment becomes a major source of fluctuations.

One of the most striking differences between the conclusions in the model with rational expectations and in the model with subjective expectations and sentiment is given by the role of technology shocks. When exogenous shifts in expectations due to sentiment are permitted in the model, sentiment accounts for a large share of cyclical fluctuations in consumption, investment, and output. 
The two technology shocks account for about a quarter or less of their changes. But when we follow the previous literature by shutting down sentiment and imposing rational expectations (and hence implicitly assuming that any learning that may have taken place has already converged to the rational expectations equilibrium), the contribution of technology jumps to levels around $80 \%$ of fluctuations, in line with the RBC literature view, to capture the now omitted role of sentiment. For the case of inflation, technology and markup shocks rise to close the gap created by the omission of sentiment.

Overall, the results show that macroeconomic models may miss an important channel by removing, by assumption, sentiment, or similar psychological forces, from their analyses.

5.3. But Is It Really Sentiment? In the estimation, we have identified sentiment as the component of expectations that cannot be rationalized as coming from a near-rational forecasting model, which allows for learning by economic agents. But sentiment in the model is obtained without using any data and information that may reflect actual sentiment, optimism or pessimism, degree of confidence, and so forth, in the economy. Can the new disturbances be really interpreted as sentiment then? In this section, we provide evidence that the identified sentiment shocks are really related to excess optimism and pessimism in expectations about the future state of the economy, even if no sentiment data were used in their calculation.

Figure 8 shows that our sentiment shocks indeed capture exogenous shifts in aggregate optimism and pessimism. Using the available survey indicators of sentiment can be informative. The figure shows scatter plots between the consumption sentiment (top-left panel) and the investment sentiment (remaining three panels) disturbances obtained from the DSGE model estimation, and the purified (or exogenous) components obtained by regressing the corresponding survey sentiment indicators on a vector of endogenous variables (detrended output, inflation, interest rates). The first panel relates the model-implied consumer sentiment shock to the exogenous component of the University of Michigan Consumer Sentiment Index (using the same 1981-2011 sample). The second panel matches the model's investment sentiment series to the purified Business Confidence Indicator obtained from the OECD's Business Tendency Surveys for Manufacturing, USA. The bottom panels compare the obtained investment sentiment to the 'CFO Expectations Index: percentage of responders feeling more optimistic about the U.S. economy' and the 'CFO Expectations Index: percentage of responders feeling more pessimistic about the U.S. economy', respectively. Both series are published as part of Duke Fuqua School of Business' CFO Magazine Business Outlook Survey; the data are available starting from 2001. 
The scatter plots reveal a strong positive relation between our model-based sentiment shocks and the observed sentiment indicators obtained from survey data and purified from their dependence on macroeconomic variables. The correlation coefficients are slightly above 0.5 between model and survey's consumption sentiment series and between model and survey's investment sentiment series. The DSGE investment sentiment series has a 0.44 correlation with the CFO's optimism index and -0.49 correlation with the pessimism index.

In the following section, we provide further evidence on the validity of the sentiment interpretation by repeating the analysis with the inclusion of survey sentiment indicators to the set of observables that need to be matched in the estimation.

\section{Robustness Analysis}

In this section, I investigate the sensitivity of the main results to a range of alternative assumptions. First, the estimation is repeated under an alternative detrending assumption, by assuming a recursively-updated linear trend.

Second, I also show the results obtained under the initialization of the learning process that was not favored by the data, and which consisted in fixing the initial beliefs at their REE value for the pre-sample, 1964-1981, period.

In the benchmark estimation, agents are assumed to observe the values of endogenous variables, but, as econometricians, are unable to observe disturbances. This choice seems more empirically realistic and satisfies the principle of "cognitive consistency" (e.g., Chung and Xiao, 2013), the symmetry in knowledge between agents within the model and researchers working with the model. I partially relax this assumption here, by assuming that agents are at least able to approximate the unobserved VARMA(1,1) structure with a higher-order $\operatorname{VAR}(2)$, which they use as their PLM.

As a final check, I repeat the estimation by adding observable survey data on sentiment in the estimation and requiring the DSGE sentiment disturbances to match such observables. Measurement error is added to allow for a non-structural stochastic component. The following measurement equations, relative to sentiment, are added to the existing set of measurement equations collected in (4.1):

$$
\begin{aligned}
\text { Survey Consumer Sent } & =h_{0}^{c s}+h_{1}^{c s} \alpha_{t}^{c}+m e_{t}^{c} \\
\text { Survey Business Sent } & =h_{0}^{b s}+h_{1}^{b s} \alpha_{t}^{i}+m e_{t}^{i},
\end{aligned}
$$

where I use the University of Michigan Consumer Sentiment Index and the Business Confidence Surveys: Business Confidence Index (both purified of their endogenous components as described in 
the previous section) as observable series, $h_{0}^{c s}, h_{1}^{c s}, h_{0}^{b s}, h_{1}^{b s}$, are coefficients, and where $m e_{t}^{c}$ and $m e_{t}^{i}$ denote measurement error terms, which are i.i.d. and with mean zero and variances $\sigma_{m e_{c}}^{2}, \sigma_{m e_{i}}^{2}$.

The posterior estimates for the various robustness checks are shown in Table 3. There are no major shifts in the estimates, except possibly that the serial correlation of the inflationary sentiment term is reduced under the REE initialization, and the reduction in the role of mechanical sources of persistence is more limited when agents adopt an expanded $\operatorname{VAR}(2)$ specification as their PLM.

The bottom rows in Table 3 illustrate the variance decomposition outcomes obtained in the different cases. The shares of economic fluctuations that can be attributed to sentiment shocks remain in line with those discussed in the paper. They range from $39 \%$ to $54 \%$ for the role of sentiment in output, and they also rise in different instances to $70 \%$ or more for consumption and investment. Sentiment is typically found to be a key determinant of inflation, with shares between $54 \%$ and $77 \%$, but with the exception of the estimation with REE initial beliefs, where the share declines to $16 \%$.

\section{Conclusions}

The role of psychological factors in booms and busts has been emphasized in the early stages of economic thought by prominent economists as Keynes and Pigou, and it still prominently features in discussions about business cycles by economic observers. Yet, current macroeconomic theory, and particularly empirical work in macroeconomics, have taken another route and typically abstract from psychology almost entirely.

This paper suggested an approach to reintroduce psychology at the center of macroeconomic analysis, by modeling 'sentiment' in a microfounded DSGE model of the U.S. economy. The paper's main objective was to investigate whether the typically omitted sentiment matters for aggregate fluctuations.

The empirical results indeed show that the literature should probably take sentiment and psychological elements more seriously. Sentiment shocks are found to explain more than forty percent of U.S. output fluctuations at business cycle horizons. The main contributor to fluctuations is, in particular, sentiment associated to expectations regarding future investment decisions. Sentiment also explains a large portion of the variability in inflation rates.

\section{REFERENCES}

[1] Angeletos, G.M., and J. La'O, 2013. "Sentiments," Econometrica, 81(2), 739-779.

[2] Aruoba, S.B., and F. Schorfheide, 2011. "Sticky Prices versus Monetary Frictions: An Estimation of Policy Trade-Offs," American Economic Journal: Macroeconomics, 3(1), 60-90.

[3] Beaudry, P., and F. Portier, 2006. "Stock Prices, News, and Economic Fluctuations," American Economic Review, vol. 96(4), 1293-1307. 
[4] Benhabib, J. and R.E.A. Farmer, 1999. "Indeterminacy and Sunspots in Macroeconomics," in (J.B. Taylor and M. Woodford, eds.), Handbook of Macroeconomics, vol. 1, part 1, pp. 387-448, Amsterdam: Elsevier.

[5] Blanchard, O.J., L'Huillier, J.P., and G. Lorenzoni, 2013. "News, Noise, and Fluctuations: An Empirical Exploration," American Economic Review, 103(7), 3045-3070.

[6] Bloom, N., 2009. "The Impact of Uncertainty Shocks," Econometrica, 77(3), 623-685.

[7] Bullard, J., Evans, G. and S. Honkapohja, 2008. "Monetary Policy, Judgment and Near-Rational Exuberance," American Economic Review, vol. 98, pp. 1163-77.

[8] Canova, F., 2014. "Bridging DSGE Models and the Raw Data", Journal of Monetary Economics, 67, 115.

[9] Canova, F., and F. Ferroni, 2011. "Multiple Filtering Devices for the Estimation of Cyclical DSGE Models," Quantitative Economics, vol. 2(1), 73-98.

[10] Christiano, L.J., Eichenbaum, M., and C.L. Evans, 2005. "Nominal Rigidities and the Dynamic Effects of a Shock to Monetary Policy," Journal of Political Economy 113, 1-45.

[11] Chung, H., and W. Xiao, 2013. "Cognitive Consistency, Signal Extraction, and Macroeconomic Persistence", mimeo, SUNY Binghamton.

[12] De Grauwe, P., 2012. Lectures on Behavioral Macroeconomics, Princeton University Press: Princeton, NJ.

[13] Del Negro, M. and S. Eusepi, 2011. "Fitting Observed Inflation Expectations", Journal of Economic Dynamics and Control, 35(12), 2105-2131.

[14] Del Negro, M., Schorfheide, F., Smets, F., and R. Wouters, 2007. "On the Fit of New Keynesian Models," Journal of Business $\&$ Economic Statistics, 25, 123-143.

[15] Eusepi, S., and B. Preston, 2011. "Expectations, Learning, and Business Cycle Fluctuations," American Economic Review, 101(6), 2844-72.

[16] Evans, G. W. and Honkapohja, S. (2001). Learning and Expectations in Economics. Princeton: Princeton University Press.

[17] Fujiwara, I., Hirose, Y., and M. Shintani, 2011. "Can News Be a Major Source of Aggregate Fluctuations? A Bayesian DSGE Approach", Journal of Money, Credit and Banking 43(1), 129.

[18] Hirose, Y., and T. Kurozumi, 2012. "Identifying News Shocks with Forecast Data," CAMA Working Papers 2012-01, Australian National University, Centre for Applied Macroeconomic Analysis.

[19] Jaimovich, N., and S. Rebelo, 2009. "Can News about the Future Drive the Business Cycle?," American Economic Review, vol. 99(4), 1097-1118.

[20] Justiniano, A., Primiceri, G.E., and A. Tambalotti, 2010. "Investment Shocks and Business Cycles," Journal of Monetary Economics, vol. 57(2), 132-145.

[21] Khan, H.U., and J. Tsoukalas, 2012. "The Quantitative Importance of News Shocks in Estimated DSGE Models", Journal of Money, Credit and Banking, 44(8), 15351561.

[22] Lubik, T.A., and F. Schorfheide, 2004. "Testing for Indeterminacy: An Application to U.S. Monetary Policy," American Economic Review, 94(1), 190-217.

[23] Milani, F., 2007. "Expectations, Learning and Macroeconomic Persistence", Journal of Monetary Economics, 54(7), 2065-2082.

[24] Milani, F., 2011. "Expectation Shocks and Learning as Drivers of the Business Cycle", Economic Journal, 121(552), 379-401.

[25] Milani, F., 2012a. "The Modeling of Expectations in Empirical DSGE Models: a Survey", Advances in Econometrics, 28, 3-38.

[26] Milani, F., and A. Rajbhandari, 2012a. "Expectation Formation and Monetary DSGE Models: Beyond the Rational Expectations Hypothesis", Advances in Econometrics, 28, 253-288.

[27] Milani, F., and A. Rajbhandari, 2012b. "Observed Expectations, News Shocks, and the Business Cycle", Working Paper 12-13-05, UC Irvine.

[28] Milani, F., and J. Treadwell, 2012. "The Effects of Monetary Policy "News" and "Surprises"”, Journal of Money, Credit and Banking, 44(8), 1667-1692.

[29] Nakamura, E., and J. Steinsson, 2008. "Five Facts about Prices: A Reevaluation of Menu Cost Models," The Quarterly Journal of Economics, 123(4), 1415-1464.

[30] Ormeno, A., 2011. 'Disciplining Expectations: Using Survey Data in Learning Models', Working Paper, Universitat Pompeu Fabra.

[31] Pigou, A.C., 1927. Industrial Fluctuations, London: MacMillan.

[32] Sargent, T.J., 1993. Bounded Rationality in Macroeconomics, Oxford University Press: Oxford, U.K.

[33] Schmitt-Grohé, S., and M. Uribe, 2012, "What's News in Business Cycles?", Econometrica, 80(6), 2733-2764.

[34] Smets, F., and R. Wouters, 2007. "Shocks and Frictions in US Business Cycles: A Bayesian DSGE Approach," American Economic Review, 97(3), 586-606. 


\begin{tabular}{|c|c|c|c|c|c|c|c|}
\hline & "Prior Distributions & & $\overline{\overline{\text { Posterior I }}}$ & istrib & itions & & \\
\hline Param. & & Ratic & al Expectations & Sentin & ent Shocks (NS) & Sentir & ent Shocks (S) \\
\hline $\bar{\varphi}$ & $\overline{\Gamma(4,1.5)}$ & 5.96 & {$[3.83,8.41]$} & 2.67 & {$[1.94,3.74]$} & 2.69 & {$[1.90,3.66]$} \\
\hline$\sigma_{c}$ & $\Gamma(2,0.5)$ & 1.65 & {$[1.26,2.10]$} & 1.02 & {$[0.84,1.22]$} & 1.91 & {$[1.47,2.38]$} \\
\hline$h$ & $B(0.5,0.15)$ & 0.70 & {$[0.44,0.81]$} & 0.48 & {$[0.31,0.66]$} & 0.34 & {$[0.18,0.62]$} \\
\hline$\sigma_{l}$ & $\Gamma(2,0.75)$ & 1.27 & {$[0.47,2.70]$} & 1.59 & {$[0.57,2.95]$} & 1.87 & {$[0.73,3.29]$} \\
\hline$\xi_{w}$ & $B(0.7,0.1)$ & 0.80 & {$[0.69,0.93]$} & 0.71 & {$[0.54,0.87]$} & 0.73 & {$[0.60,0.85]$} \\
\hline$\xi_{p}$ & $B(0.7,0.1)$ & 0.88 & {$[0.78,0.99]$} & 0.89 & {$[0.81,0.95]$} & 0.89 & {$[0.81,0.95]$} \\
\hline$\iota_{w}$ & $B(0.5,0.15)$ & 0.58 & {$[0.36,0.80]$} & 0.47 & {$[0.24,0.72]$} & 0.46 & {$[0.19,0.76]$} \\
\hline$\iota_{p}$ & $B(0.5,0.15)$ & 0.14 & {$[0.04,0.43]$} & 0.23 & {$[0.08,0.47]$} & 0.24 & {$[0.09,0.46]$} \\
\hline$\psi$ & $B(0.5,0.15)$ & 0.84 & {$[0.71,0.94]$} & 0.84 & {$[0.71,0.94]$} & 0.84 & {$[0.72,0.94]$} \\
\hline$\Phi_{p}-1$ & $\Gamma(0.25,0.12)$ & 0.38 & {$[0.20,0.66]$} & 0.55 & {$[0.29,0.83]$} & 0.53 & {$[0.32,0.79]$} \\
\hline$\rho_{r}$ & $B(0.75,0.1)$ & 0.83 & {$[0.78,0.87]$} & 0.83 & {$[0.75,0.90]$} & 0.83 & {$[0.74,0.90]$} \\
\hline$\chi_{\pi}$ & $N(1.5,0.25)$ & 1.74 & {$[1.24,2.13]$} & 1.49 & {$[1.09,1.95]$} & 1.44 & {$[1.02,1.82]$} \\
\hline$\chi_{y}$ & $N(0.125,0.05)$ & 0.06 & {$[0.02,0.10]$} & 0.06 & {$[0.02,0.11]$} & 0.06 & {$[0.02,0.12]$} \\
\hline$\rho_{g}$ & $B(0.5,0.2)$ & 0.95 & {$[0.92,0.97]$} & 0.95 & {$[0.91,0.98]$} & 0.95 & {$[0.92,0.98]$} \\
\hline$\rho_{b}$ & $B(0.5,0.2)$ & 0.23 & {$[0.04,0.78]$} & 0.10 & {$[0.02,0.22]$} & 0.08 & {$[0.02,0.18]$} \\
\hline$\rho_{i}$ & $B(0.5,0.2)$ & 0.68 & {$[0.54,0.81]$} & 0.14 & {$[0.03,0.31]$} & 0.09 & {$[0.02,0.20]$} \\
\hline$\rho_{a}$ & $B(0.5,0.2)$ & 0.97 & {$[0.93,0.99]$} & 0.95 & {$[0.90,0.98]$} & 0.95 & {$[0.91,0.98]$} \\
\hline$\rho_{p}$ & $B(0.5,0.2)$ & 0.73 & {$[0.14,0.91]$} & 0.09 & {$[0.02,0.23]$} & 0.08 & {$[0.02,0.18]$} \\
\hline$\rho_{w}$ & $B(0.5,0.2)$ & 0.18 & {$[0.05,0.35]$} & 0.13 & {$[0.03,0.26]$} & 0.10 & {$[0.02,0.22]$} \\
\hline$\rho_{g a}$ & $N(0.5,0.25)$ & 0.35 & {$[0.17,0.52]$} & 0.34 & {$[0.15,0.52]$} & 0.34 & {$[0.18,0.52]$} \\
\hline$\sigma_{g}$ & $\Gamma^{-1}(0.3,1)$ & 0.61 & {$[0.53,0.68]$} & 0.60 & {$[0.53,0.69]$} & 0.60 & {$[0.53,0.68]$} \\
\hline$\sigma_{b}$ & $\Gamma^{-1}(0.3,1)$ & 0.30 & {$[0.14,0.38]$} & 0.68 & {$[0.60,0.77]$} & 0.68 & {$[0.60,0.76]$} \\
\hline$\sigma_{i}$ & $\Gamma^{-1}(1,5)$ & 0.74 & {$[0.59,0.93]$} & 2.00 & {$[1.77,2.30]$} & 1.98 & {$[1.76,2.25]$} \\
\hline$\sigma_{a}$ & $\Gamma^{-1}(0.3,1)$ & 0.59 & {$[0.52,0.68]$} & 0.58 & {$[0.51,0.66]$} & 0.59 & {$[0.50,0.66]$} \\
\hline$\sigma_{p}$ & $\Gamma^{-1}(0.3,1)$ & 0.12 & {$[0.08,0.19]$} & 0.26 & {$[0.23,0.30]$} & 0.26 & {$[0.23,0.30]$} \\
\hline$\sigma_{w}$ & $\Gamma^{-1}(0.3,1)$ & 0.46 & {$[0.38,0.56]$} & 0.96 & {$[0.84,1.11]$} & 0.95 & {$[0.84,1.07]$} \\
\hline$\sigma_{\varepsilon}$ & $\Gamma^{-1}(0.3,1)$ & 0.17 & {$[0.15,0.19]$} & 0.20 & {$[0.18,0.23]$} & 0.20 & {$[0.18,0.23]$} \\
\hline$\rho_{\alpha_{c}}$ & $B(0.5,0.2)$ & & & 0.70 & {$[0.57,0.83]$} & 0.69 & {$[0.57,0.69]$} \\
\hline$\rho_{\alpha_{i}}$ & $B(0.5,0.2)$ & & & 0.85 & {$[0.77,0.93]$} & 0.86 & {$[0.76,0.94]$} \\
\hline$\rho_{\alpha_{\pi}}$ & $B(0.5,0.2)$ & & & 0.74 & {$[0.62,0.86]$} & 0.70 & {$[0.57,0.81]$} \\
\hline$\sigma_{\alpha_{c}}$ & $\Gamma^{-1}(0.3,1)$ & & & 0.51 & {$[0.45,0.59]$} & 0.50 & {$[0.44,0.57]$} \\
\hline$\sigma_{\alpha_{i}}$ & $\Gamma^{-1}(1,5)$ & & & 1.43 & {$[1.26,1.63]$} & 1.43 & {$[1.27,1.61]$} \\
\hline$\sigma_{\alpha_{\pi}}$ & $\Gamma^{-1}(0.3,1)$ & & & 0.12 & {$[0.10,0.13]$} & 0.12 & {$[0.11,0.14]$} \\
\hline$\overline{\mathrm{g}}$ & $B(0.025,0.01)$ & & & 0.013 & {$[0.01,0.017]$} & 0.012 & {$[0.008,0.015]$} \\
\hline
\end{tabular}

Table 1 - Prior distributions and Posterior estimates, baseline model.

Note: $\Gamma$ denotes Gamma distribution, $B$ denotes Beta distribution, $N$ denotes Normal distribution, $\Gamma^{-1}$ denotes Inverse Gamma distribution, and $U$ denotes Uniform distribution. The prior distributions are expressed in terms of mean and standard deviation, except for the Uniform prior, for which lower and upper bounds are shown. Posterior means and 95\% credible intervals have been calculated over 400,000 Metropolis-Hastings draws, discarding a burnin of $40 \%$ draws. The table reports the posterior estimates for the model under rational expectations and under learning and sentiment (for the benchmark specification with non-separable, NS, preferences and for the separable, S, alternative). The sample is 1981:III-2011:I. 


\begin{tabular}{|c|c|c|c|c|c|c|c|c|c|c|c|}
\hline & $\varepsilon_{t}^{g}$ & $\varepsilon_{t}^{b}$ & $\varepsilon_{t}^{i}$ & $\varepsilon_{t}^{a}$ & $\varepsilon_{t}^{p}$ & $\varepsilon_{t}^{w}$ & $\varepsilon_{t}^{r}$ & $\alpha_{t}^{c}$ & $\alpha_{t}^{i}$ & $\alpha_{t}^{\pi}$ & $\%$ Sentiment \\
\hline \multicolumn{12}{|c|}{ horizon $=\underline{\text { Short-Run }}(0-4)$} \\
\hline$y_{t}$ & $\begin{array}{l}0.281 \\
{[0.095]}\end{array}$ & $\begin{array}{l}0.105 \\
{[0.084]}\end{array}$ & $\begin{array}{l}0.258 \\
{[0.628]}\end{array}$ & $\begin{array}{l}0.019 \\
{[0.080]}\end{array}$ & $\begin{array}{l}0.051 \\
{[0.078]}\end{array}$ & $\begin{array}{l}0.010 \\
{[0.020]}\end{array}$ & $\begin{array}{l}0.063 \\
{[0.014]}\end{array}$ & 0.051 & 0.157 & 0.007 & $21.4 \%$ \\
\hline$c_{t}$ & $\begin{array}{l}0.001 \\
{[0.001]}\end{array}$ & $\begin{array}{l}0.425 \\
{[0.378]}\end{array}$ & $\begin{array}{l}0.019 \\
{[0.265]}\end{array}$ & $\begin{array}{l}0.001 \\
{[0.141]}\end{array}$ & $\begin{array}{l}0.058 \\
{[0.144]}\end{array}$ & $\begin{array}{l}0.008 \\
{[0.034]}\end{array}$ & $\begin{array}{l}0.137 \\
{[0.037]}\end{array}$ & 0.342 & 0.005 & 0.004 & $35.1 \%$ \\
\hline$i_{t}$ & $\begin{array}{l}0.001 \\
{[0.008]}\end{array}$ & $\begin{array}{l}0.007 \\
{[0.011]}\end{array}$ & $\begin{array}{l}0.576 \\
{[0.899]}\end{array}$ & $\begin{array}{l}0.001 \\
{[0.019]}\end{array}$ & $\begin{array}{l}0.038 \\
{[0.046]}\end{array}$ & $\begin{array}{l}0.009 \\
{[0.013]}\end{array}$ & $\begin{array}{l}0.022 \\
{[0.005]}\end{array}$ & 0.002 & 0.336 & 0.009 & $34.7 \%$ \\
\hline$\pi_{t}$ & $\begin{array}{l}0.001 \\
{[0.010]}\end{array}$ & $\begin{array}{l}0.021 \\
{[0.005]}\end{array}$ & $\begin{array}{l}0.002 \\
{[0.022]}\end{array}$ & $\begin{array}{l}0.010 \\
{[0.066]}\end{array}$ & $\begin{array}{l}0.657 \\
{[0.769]}\end{array}$ & $\begin{array}{l}0.011 \\
{[0.121]}\end{array}$ & $\begin{array}{l}0.002 \\
{[0.006]}\end{array}$ & 0.013 & 0.001 & 0.282 & $29.6 \%$ \\
\hline \multicolumn{12}{|c|}{ horizon $=\underline{\text { Business Cycle }}$ (4-24) } \\
\hline$y_{t}$ & $\begin{array}{l}0.120 \\
{[0.017]}\end{array}$ & $\begin{array}{l}0.015 \\
{[0.008]}\end{array}$ & $\begin{array}{l}0.192 \\
{[0.387]}\end{array}$ & $\begin{array}{l}0.066 \\
{[0.404]}\end{array}$ & $\begin{array}{l}0.066 \\
{[0.119]}\end{array}$ & $\begin{array}{l}0.019 \\
{[0.057]}\end{array}$ & $\begin{array}{l}0.082 \\
{[0.008]}\end{array}$ & 0.025 & 0.350 & 0.065 & $44.0 \%$ \\
\hline$c_{t}$ & $\begin{array}{l}0.024 \\
{[0.026]}\end{array}$ & $\begin{array}{l}0.043 \\
{[0.019]}\end{array}$ & $\begin{array}{l}0.113 \\
{[0.279]}\end{array}$ & $\begin{array}{l}0.053 \\
{[0.484]}\end{array}$ & $\begin{array}{l}0.113 \\
{[0.123]}\end{array}$ & $\begin{array}{l}0.025 \\
{[0.059]}\end{array}$ & $\begin{array}{l}0.228 \\
{[0.010]}\end{array}$ & 0.127 & 0.166 & 0.108 & $40.1 \%$ \\
\hline$i_{t}$ & $\begin{array}{l}0.007 \\
{[0.073]}\end{array}$ & $\begin{array}{l}0.015 \\
{[0.002]}\end{array}$ & $\begin{array}{c}0.248 \\
{[0.660]}\end{array}$ & $\begin{array}{l}0.015 \\
{[0.139]}\end{array}$ & $\begin{array}{l}0.044 \\
{[0.081]}\end{array}$ & $\begin{array}{l}0.019 \\
{[0.040]}\end{array}$ & $\begin{array}{l}0.037 \\
{[0.004]}\end{array}$ & 0.037 & 0.531 & 0.047 & $61.5 \%$ \\
\hline$\pi_{t}$ & $\begin{array}{l}0.009 \\
{[0.054]}\end{array}$ & $\begin{array}{l}0.064 \\
{[0.005]}\end{array}$ & $\begin{array}{l}0.078 \\
{[0.398]}\end{array}$ & $\begin{array}{l}0.045 \\
{[0.149]}\end{array}$ & $\begin{array}{l}0.062 \\
{[0.250]}\end{array}$ & $\begin{array}{l}0.098 \\
{[0.130]}\end{array}$ & $\begin{array}{l}0.063 \\
{[0.015]}\end{array}$ & 0.119 & 0.135 & 0.327 & $58.1 \%$ \\
\hline
\end{tabular}

Table 2 - Forecast Error Variance Decomposition.

Note: The main entries refer to the model estimation with observed expectations, learning and sentiment. The numbers below in brackets refer to the estimation under rational expectations. 


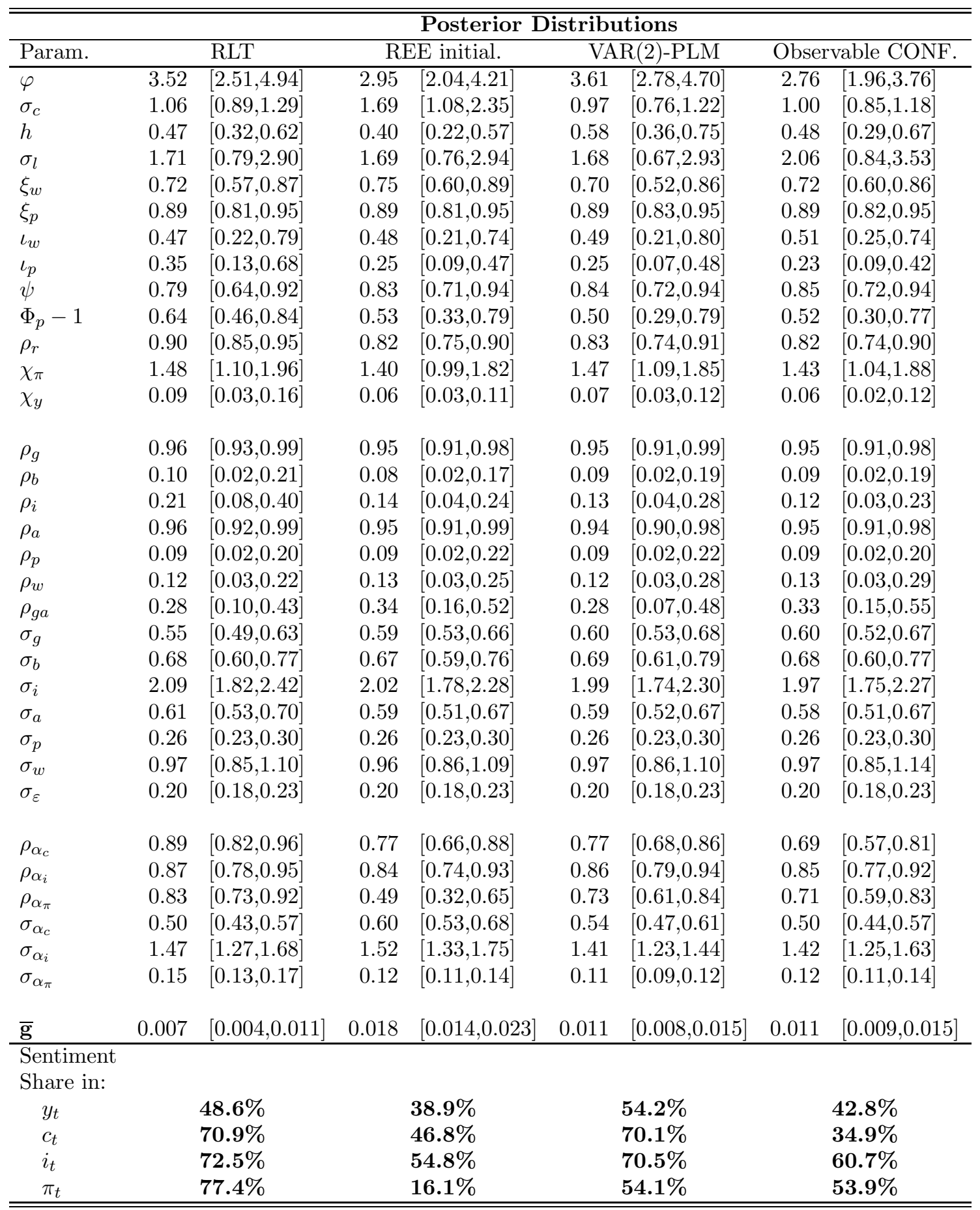

Table 3 - Posterior estimates, robustness checks.

Note: The first column reports the results for the estimation using a recursively updated linear trend as detrending option. The second column reports the results under a different initialization of the agents' learning process: agents' initial beliefs correspond to those in the rational expectations equilibrium (REE) for the previous sample (1964-1981). The third columns shows the results obtained under a different perceived law of motion (PLM): agents use a VAR(2) as their PLM, rather than the benchmark VAR(1). The fourth column shows the results obtained for the estimation in which data on consumer confidence and business confidence are included to the list of observables. Sentiment in the model is linked to the observable series up to an i.i.d. measurement error. For each robustness check, we show posterior mean estimates, 2.5 and 97.5 percentiles, and the shares of forecast error variance in output, consumption, investment, and inflation, that can be explained by the ensemble of sentiment shocks. 

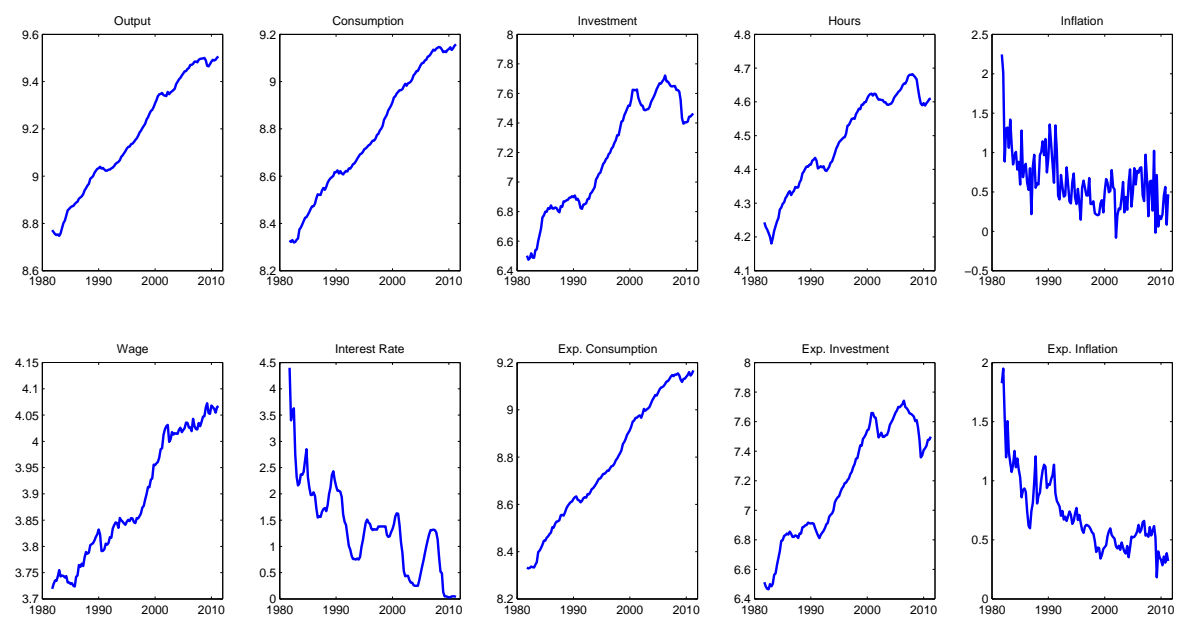

Figure 1. Raw Data Series. Note: output, consumption, investment, wage, consumption expectations, investment expectations are all expressed in real terms and are reported in log levels; hours are also in log levels. The interest rate is levels and converted to quarterly, while inflation and expected inflation are obtained as the $\log$ first difference of the price level. All data correspond to real-time vintages (the series were redefined to maintain the same base year across the sample, when necessary). 

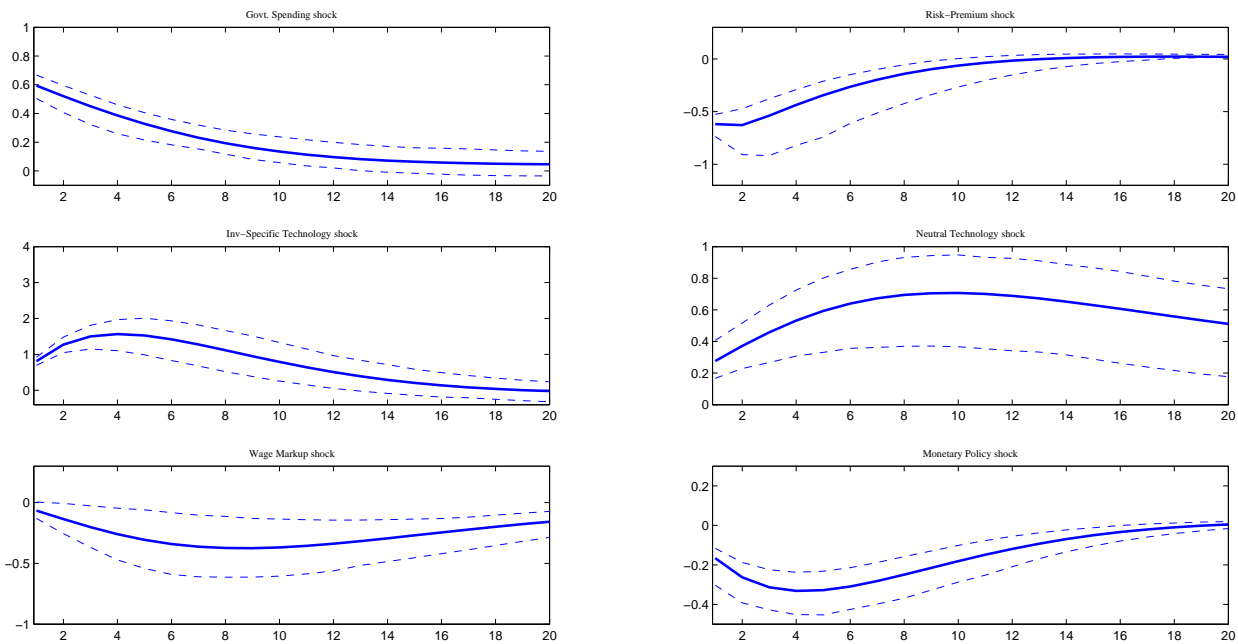

FigURE 2. Impulse response functions of output $y_{t}$ to government spending, risk-premium, investment-specific technology and neutral technology shocks, wage markup shocks, and monetary policy shocks, under rational expectations. The graphs show mean impulse responses across MCMC draws, along with 5\% and 95\% percentile error bands.
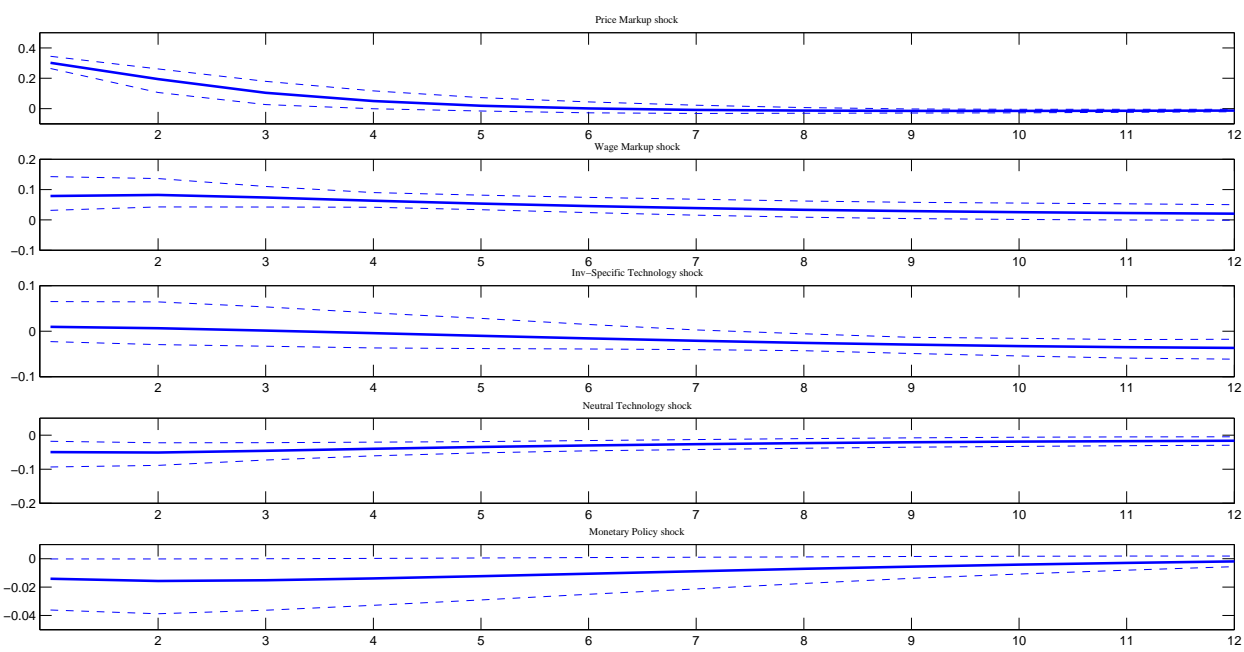

FigURE 3. Impulse response function of $\pi_{t}$ to price markup, wage markup, investment-specific, neutral technology, and monetary policy shocks, under rational expectations. The graphs show mean impulse responses across MCMC draws, along with $5 \%$ and $95 \%$ percentile error bands. 

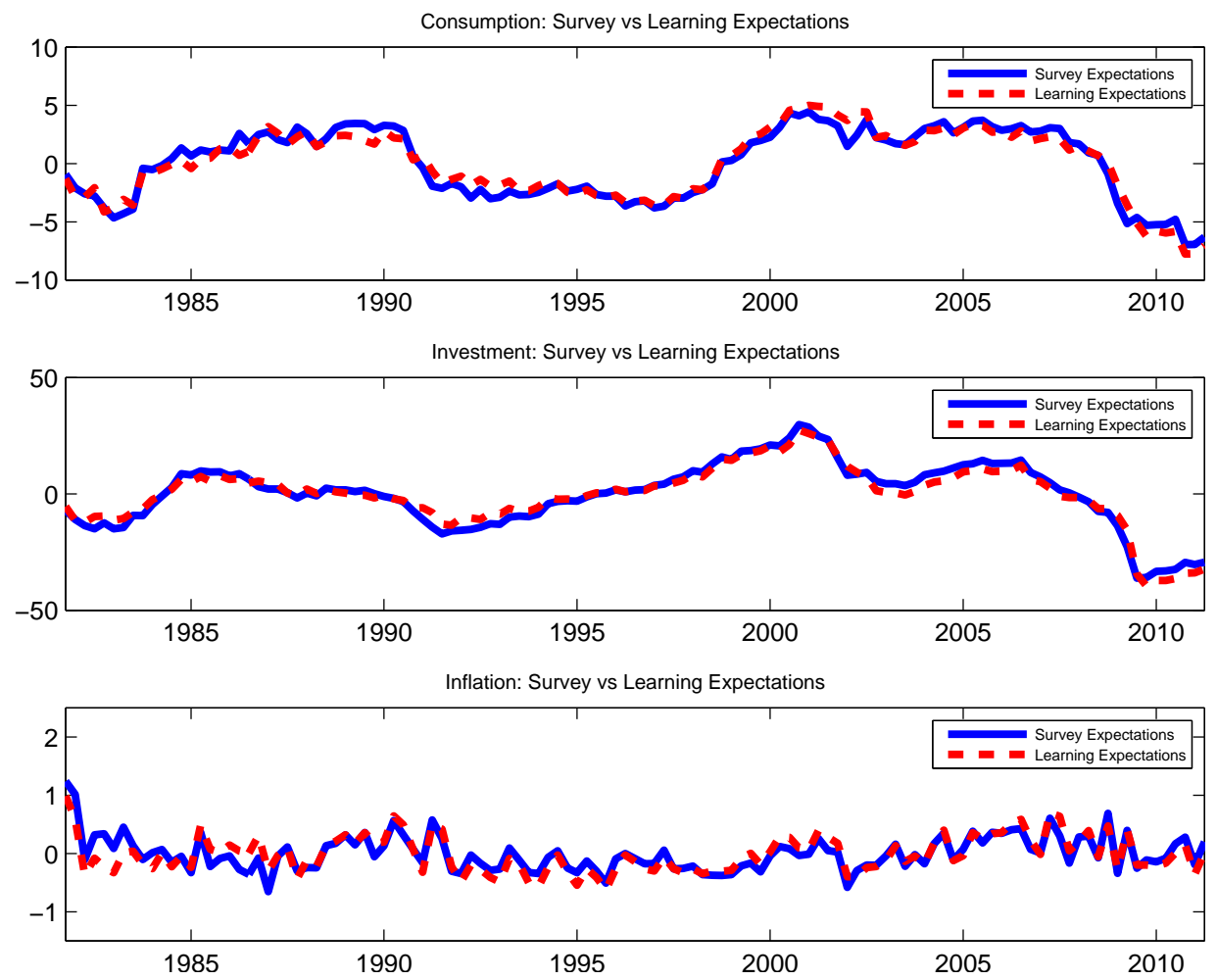

FIGURE 4. Survey-based expectations versus near-rational expectations from learning model. The solid blue lines indicate survey expectations from the Survey of Professional Forecasters for consumption, investment, and inflation. The dashed red lines refer to the model-implied expectations, based on the near-rational learning model. They represent the endogenous component of expectations (i.e., the part that reflects an adjustment of expectations based on the state of the economy, excluding sentiment). 

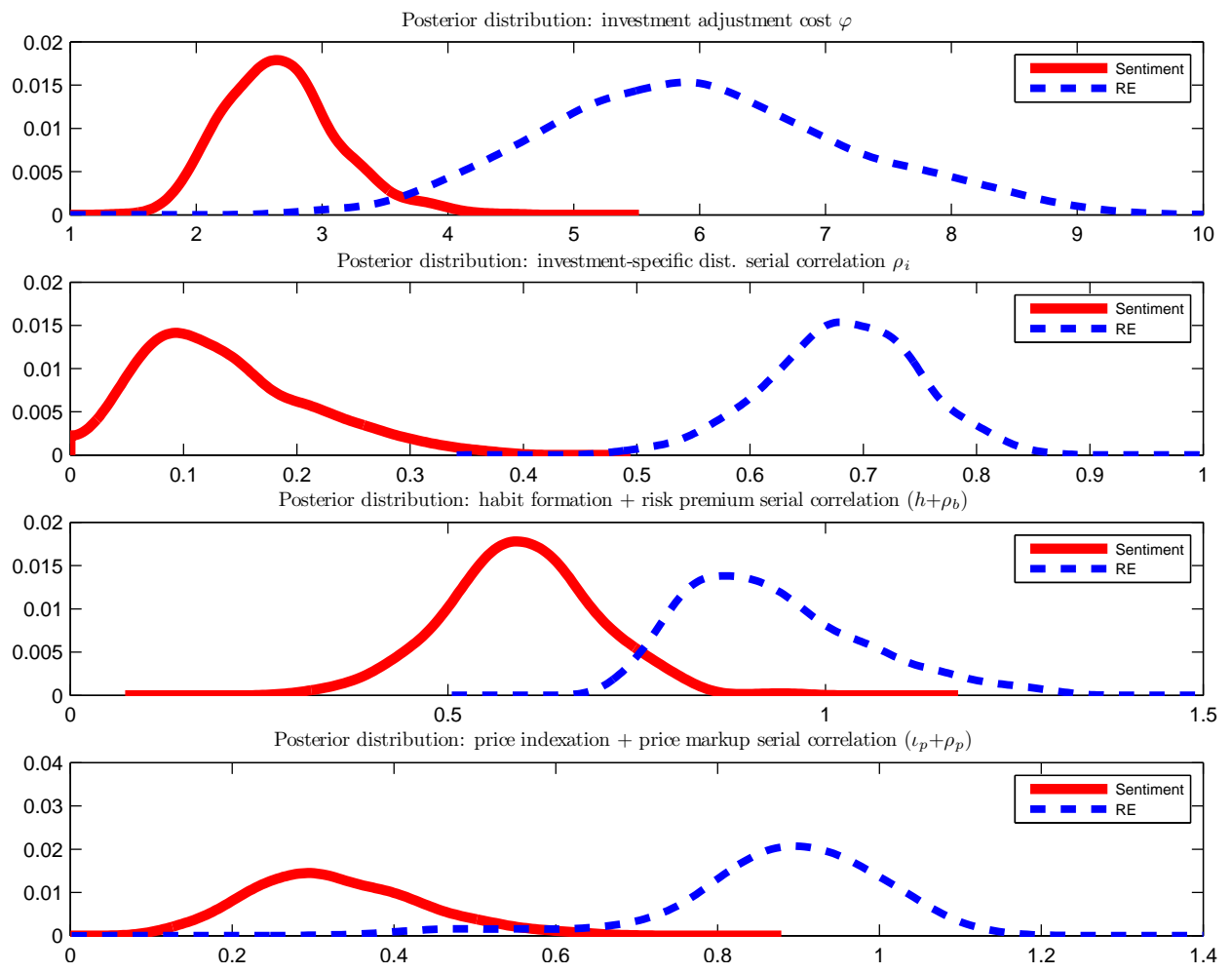

Figure 5. Posterior Distributions: Endogenous and Exogenous Sources of Persistence. Note: the top panel shows the posterior distributions for the investmentadjustment cost coefficient. The solid red line refers to the distribution obtained from the model with subjective expectations, learning, and sentiment, the dashed blue line to the distribution obtained from the rational expectations estimation. The second panel shows the posterior distribution for the autoregressive coefficient related to the investment-specific technology disturbance. The third panel shows the posterior distribution for the sum of the habit formation in consumption coefficient and the serial correlation of the risk-premium shock. The bottom panel shows the posterior distribution for the sum of the inflation indexation coefficient and the serial correlation of the price markup shock. 

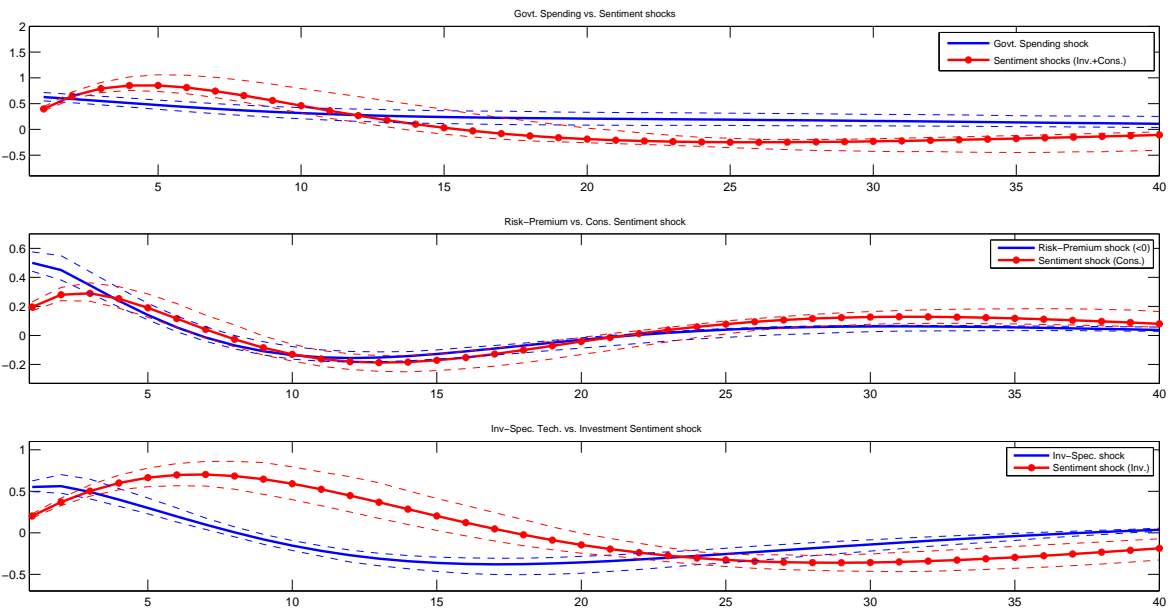

FigURE 6. Impulse response function of $y_{t}$ to structural and sentiment shocks, under observed expectations. The structural shocks considered are government spending, risk-premium, and investment-specific. The sentiment shocks are those related to consumption and investment expectations.
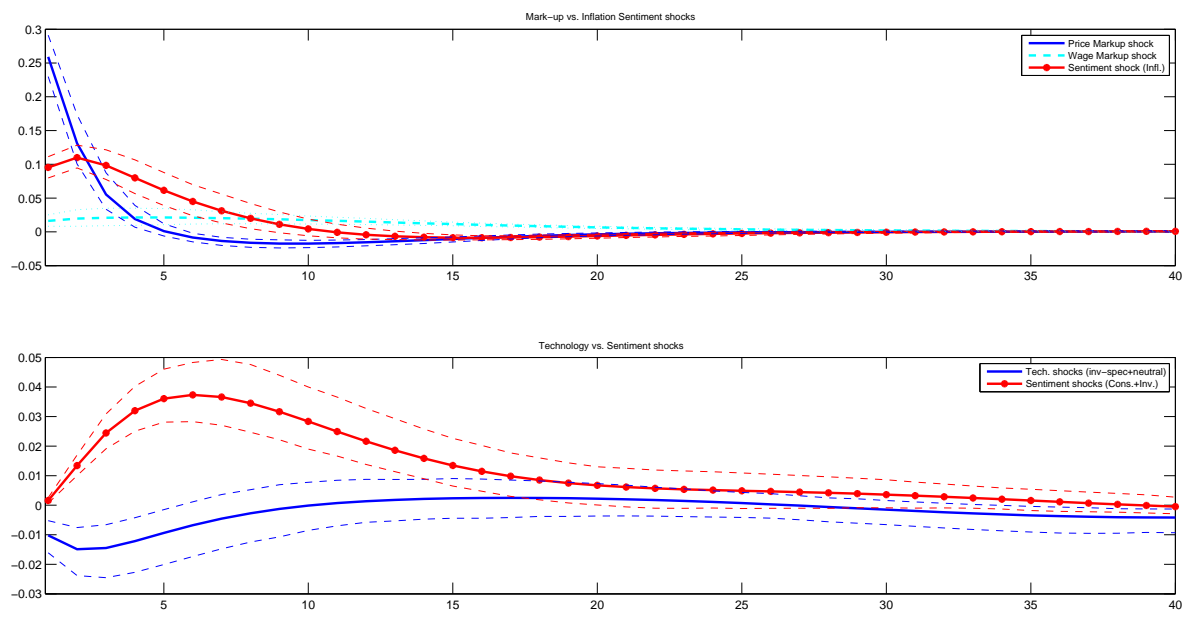

FigURE 7. Impulse response function of inflation to structural and sentiment shocks, under observed expectations. The top panel shows the responses to price markup, wage markup, and inflation sentiment shocks. The bottom panel shows the sum of the responses to the investment-specific and technology shocks, together with the sum of the responses to the consumption and investment sentiment shocks. 

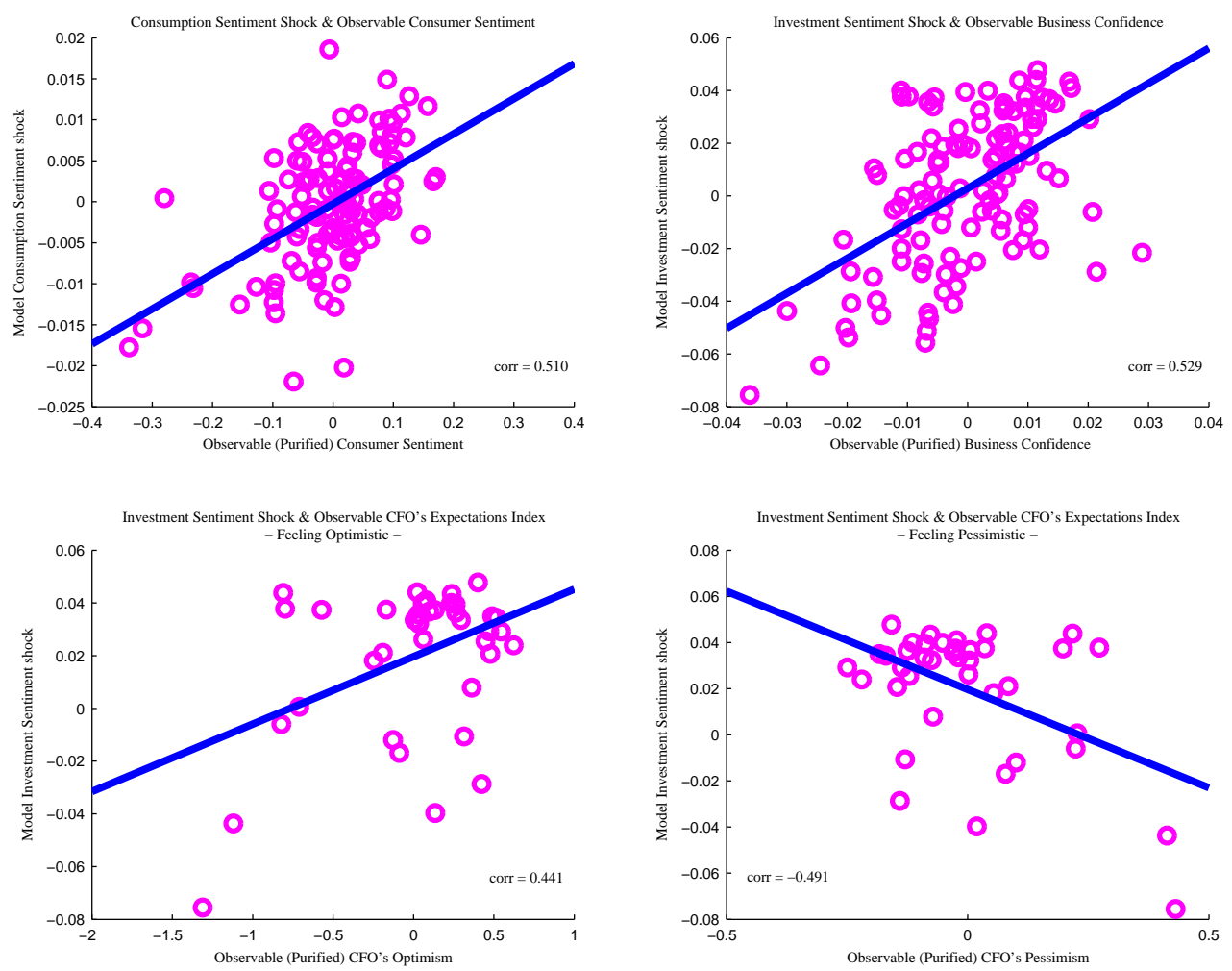

FIGURE 8. Scatter plots: sentiment shocks from DSGE model estimation versus observed survey sentiment indicators (purified component). The upper left scatter plot shows the relation (with OLS regression line) between the DSGE-model-based consumption sentiment shock and the exogenous component of the University of Michigan Consumer Sentiment series (obtained by regressing the sentiment index on economic indicators, specifically output, inflation, interest rates). The upper right scatter plot shows the relation between the DSGE-model-based investment sentiment shock and the exogenous component in the Business Confidence Index (obtained by regressing the dependent variable on the same vector of economic indicators). The two bottom panels show the relation between the same model-based investment sentiment and the CFO's optimism index (business executive responders feeling optimistic about future business conditions) and the CFO's pessimism index (business executive responders feeling pessimistic about future business conditions), respectively. Both are also purified to extract the exogenous component of the indexes. The implied correlation coefficients are superimposed on every panel. 